\title{
Lesions of an Avian Forebrain Nucleus That Disrupt Song Development Alter Synaptic Connectivity and Transmission in the Vocal Premotor Pathway
}

\author{
J. Matthew Kittelberger and Richard Mooney \\ Department of Neurobiology, Duke University Medical Center, Durham, North Carolina 27710
}

The avian forebrain nucleus, the lateral magnocellular nucleus of the anterior neostriatum (LMAN), is necessary for normal song development because LMAN lesions made in juvenile birds disrupt song production but do not disrupt song when made in adults. Although these age-limited behavioral effects implicate LMAN in song learning, a potential confound is that LMAN lesions could disrupt normal vocal motor function independent of any learning role by altering LMAN's premotor target, the song nucleus, the robust nucleus of the archistriatum (RA). To date, however, no studies have examined directly the effects of LMAN lesions on the circuitry of the RA. We report here that juvenile LMAN lesions rapidly and profoundly affect RA, altering synaptic connectivity within this nucleus, including descending inputs from the song nucleus HVc. Specifically, morphological assays of the dendritic spines of RA projection neurons and axon terminal boutons arising from HVc show a numerical decline in the density of connections in RA in LMAN- lesioned juveniles compared with controls. Concurrently, LMAN lesions alter excitatory transmission within the juvenile RA: after LMAN lesions, the stimulus-response relationship between HVc fibers and RA neurons steepens, and the amplitude of spontaneous monophasic EPSCs increases. Rather than arresting $R A$ in a juvenile state, LMAN lesions transform the structure and function of RA and its connections, such that it is distinct from that of the normal juvenile. In many ways, RA circuitry in LMAN-lesioned juveniles resembles that of normal adults, suggesting that LMAN lesions induce a premature maturation of the vocal motor pathway, which may lead to a loss of behavioral plasticity and abnormal song development.

Key words: RA; LMAN; lesions; zebra finch; vocal plasticity; song learning; song nuclei; dendritic spines; homeostatic regulation; excitatory synaptic transmission; trophic effects; synaptic connectivity
Avian song learning involves sensory acquisition, when juvenile birds memorize a tutor's song, and sensorimotor learning, when birds use auditory feedback to vocally match the memorized model (Konishi, 1965; Immelmann, 1969; Price, 1979) (for review, see Mooney, 1999). At sexual maturation [approximately posthatch day (PHD) 90 in zebra finches], song "crystallizes" into a stable form, losing its juvenile variability (Immelmann, 1969). The neural substrate for song production and development is a series of forebrain and brainstem nuclei (see Fig. $1 A$ ). This "song system" includes a vocal motor pathway, required for singing (Nottebohm et al., 1976, 1982; Vicario, 1993; Wild, 1993a,b), and an anterior forebrain pathway, needed for song development but not for adult singing (Okuhata and Saito, 1987; Bottjer et al., 1989). The robust nucleus of the archistriatum (RA) is the major site of convergence between these two pathways. RA projection neurons, which innervate brainstem nuclei controlling vocalization, receive afferents from both $\mathrm{HVc}$ (used here as a proper name) and the lateral magnocellular nucleus of the anterior neostriatum (LMAN), the anterior forebrain pathway output,

\footnotetext{
Received June 7, 1999; revised Aug. 12, 1999; accepted Aug. 18, 1999.

This research was supported by National Institutes of Health Grant R01 DC02524 and McKnight, Klingenstein, and Sloan Foundation Awards to R.M., and by a Howard Hughes Medical Institute Pre-doctoral Fellowship to J.M.K. We thank Rebecca Stacy for assistance with some early camera lucida reconstructions and the design of morphological data analyses. We also thank David Fitzpatrick and the members of the Mooney lab for providing thoughtful comments on earlier versions of this manuscript.

Correspondence should be addressed to Dr. Richard Mooney, Department of Neurobiology, Box 3209, Duke University Medical Center, Durham, NC 27710. E-mail: mooney@neuro.duke.edu.

Copyright (c) 1999 Society for Neuroscience $\quad 0270-6474 / 99 / 199385-14 \$ 05.00 / 0$
}

and are thus one cellular site of this convergence (Mooney and Konishi, 1991).

LMAN lesions in juvenile zebra finches dramatically disrupt song development. When LMAN is lesioned at the height of sensorimotor learning (PHD 35-50), song degrades quickly into a highly repetitive and simplified form, often consisting of only a few abnormally structured notes (Bottjer et al., 1984; Scharff and Nottebohm, 1991). In contrast, adult LMAN lesions do not affect song (Bottjer et al., 1984). To understand how LMAN lesions perturb song development, it is necessary to determine the consequences of juvenile LMAN lesions on the structure and function of RA, LMAN's premotor target.

One idea is that juvenile LMAN lesions, which reduce vocal plasticity, block cellular changes in RA that are required for song development. For example, developmental changes in RA's intrinsic connections, or its premotor inputs from $\mathrm{HVc}$, may be prevented. A second idea is that LMAN lesions disrupt song development by inducing abnormal changes in RA circuitry. These changes could be regressive, involving neuronal atrophy, or progressive, precipitating RA's premature maturation. In this latter case, juvenile LMAN lesions could mimic the normal developmental decline in LMAN terminals within RA (Herrmann and Arnold, 1991), which may regulate RA circuit maturation. Either regressive or progressive changes would imply that LMAN actively maintains RA's phenotype in normal juveniles. Consistent with such a trophic role for LMAN, lesions made much earlier (about PHD 20) cause profound RA cell death (Akutagawa and Konishi, 1994; Johnson and Bottjer, 1994), which is prevented by infusing neurotrophins into RA (Johnson 
et al., 1997). Later LMAN lesions (about PHD 40-50) disrupt song development without causing RA cell death (Johnson and Bottjer, 1994), although whether these lesions more subtly disrupt RA circuitry remains unknown. If LMAN trophically maintains RA circuitry during sensorimotor learning, then song disruption after juvenile LMAN lesions may reflect changes in RA caused by decreased trophic support. These two ideas (i.e., stabilization vs change) allow distinct predictions to be made about cellular consequences of LMAN lesions within RA. We show here that juvenile LMAN lesions induce both structural and functional changes in RA neurons, rather than fixing them in their normal juvenile state. Furthermore, these lesion-induced changes mimic normal developmental changes that occur over sensorimotor learning. Taken together, these results suggest that LMAN trophically regulates RA's maturation, thereby limiting periods of vocal plasticity.

\section{MATERIALS AND METHODS}

Animals. All experiments were performed on male zebra finches (Taeniopygia guttata), ranging from PHD 20 to 300, from our breeding colony, using protocols approved by the Duke University Institutional Animal Care and Use Committee. Three age ranges were used: "fledglings," between PHD 20 and 30, have not begun to sing and are in the sensory acquisition phase of song learning (Immelmann, 1969); "juveniles" (PHD 40-50) are in the early phase of sensorimotor learning, have a highly plastic song (Slater et al., 1988), and are of an age when LMAN lesions exert their most deleterious effects on song (Bottjer et al., 1984) without causing cell death in RA (Johnson and Bottjer, 1994); "adults" (>PHD 90) sing stable "crystallized" songs (Immelmann, 1969) that are not disrupted by LMAN lesions.

Preparation of acute brain slices. Details for preparation of the in vitro brain slices have been described previously (Mooney and Konishi, 1991). Briefly, a bird was anesthetized with Metofane (Mallinckrodt Veterinary, Mundelein, IL) and decapitated. The brain was removed, chilled in oxygenated artificial CSF (ACSF; $4^{\circ} \mathrm{C}$, equilibrated with $95 \% \mathrm{O}_{2} /$ $5 \% \mathrm{CO}_{2}$ ), and sectioned sagitally into $450-500 \mu \mathrm{m}$ slices on a vibratome (Series 1000 Model, Ted Pella, Redding, CA). Slices were transferred immediately to an interface-type holding chamber and maintained at room temperature for $1.5-2 \mathrm{hr}$ before recording. ACSF consisted of (in $\mathrm{mm}$ ): $\mathrm{NaCl} 119, \mathrm{KCl} 2.5, \mathrm{MgCl}_{2} 1.3, \mathrm{CaCl}_{2} 2.5, \mathrm{NaH}_{2} \mathrm{PO}_{4} 1.0, \mathrm{NaHCO}_{3}$ 26.2, and glucose 11. Equiosmolar sucrose was substituted for $\mathrm{NaCl}$ during tissue preparation. All reagents for ACSF were obtained from Mallinckrodt Specialty Chemical (Paris, KY), except for $\mathrm{MgCl}_{2}$ and $\mathrm{CaCl}_{2}$, which were from Sigma (St. Louis, MO).

Sharp microelectrode intracellular recordings and cell fills. Sharp intracellular recordings of RA projection neurons were made in an interfacetype chamber (Medical Systems, Greenvale, NY) at $30^{\circ} \mathrm{C}$, using borosilicate glass pipettes (BF-100-50-10, Sutter Instruments, Fountain Valley, CA) pulled to a final resistance of $100-180 \mathrm{M} \Omega$ on a Flaming/Brown Micropipette Puller (Model P-97, Sutter Instruments) and filled with $2 \mathrm{M}$ potassium acetate (Mallinckrodt) and $7.5 \%$ neurobiotin (Vector Laboratories, Burlingame, CA) filtered to $0.2 \mu \mathrm{m}$. Microelectrodes were positioned over RA with a Newport micromanipulator (Newport Instruments) and advanced through the nucleus with a Newport Motorizer mated to the $z$-axis of the manipulator. Intracellular potentials were amplified a total of 50 times with an Axoclamp 2B intracellular amplifier (Axon Instruments, Foster City, CA) in bridge mode and an instrumentation amplifier (Brownlee, Sunnyvale, CA), low-pass-filtered at $1-3 \mathrm{kHz}$, and digitized at $10 \mathrm{kHz}$. Data acquisition was performed with a National Instruments (Austin, TX) data acquisition board (AT-MIO-16E2), controlled by custom LabVIEW software written by Fred Livingston and Rob Neummann (Duke University). After electrophysiological data were acquired, neurobiotin was iontophoresed into the cell with depolarizing current $(0.4-0.8 \mathrm{nA}, 500 \mathrm{msec} / \mathrm{sec}$, for $15-30 \mathrm{~min})$. The slice was then returned to the holding chamber for an additional 30-60 min (room temperature) to maximize diffusion of the tracer throughout the cell. Slices were then fixed in $4 \%$ paraformaldehyde in $25 \mathrm{~mm}$ sodium phosphate buffer for at least $12 \mathrm{hr}$ at $4^{\circ} \mathrm{C}$.

During recording, RA projection neurons were identified on the basis of their tonic firing activity and characteristic spike shape (Mooney, 1992; Spiro et al., 1999). All neurons used in these analyses were histologically confirmed to be projection neurons based on the morphological criteria of having a cell body and dendritic field confined within the boundary of RA (defined by Nissl stain), a main axon exiting across the rostral RA boundary, and spinous dendrites.

Bipolar stimulating electrodes were placed in the fiber tract from $\mathrm{HVc}$ to RA for those experiments in which postsynaptic potentials (PSPs) were evoked from RA projection neurons by electrical stimulation of $\mathrm{HV}$ c fibers. Stimulation currents $(10-900 \mu \mathrm{A})$ were delivered using an Isolator-10 stimulus isolation unit (Axon Instruments). Stimulating electrodes used in most experiments were of concentric bipolar design (FHC, Brunswick, ME), although in several early experiments bipolar electrodes fabricated from a pair of monopolar tungsten microelectrodes (MicroProbe, Clarksburg, MD) were also used. There were no differences between results obtained using the different types of stimulating electrodes, so all of the evoked PSP data reported were pooled from experiments using the two types of stimulating electrodes.

Whole-cell voltage-clamp recordings. Slices for whole-cell recording were made as described above and submerged in a superfusion chamber (at room temperature) perfused continuously with oxygenated ACSF containing $50 \mu \mathrm{M}$ picrotoxin (Sigma) to block GABA receptor-mediated IPSCs. Details for the recording of whole-cell currents were as previously described (Livingston and Mooney, 1997). Patch pipettes (2.5-5 $\mathrm{M} \Omega$ ) were filled with an internal solution consisting of (in $\mathrm{mM}$ ): 100 $\mathrm{K}^{+}$-gluconate (Fluka, Ronkonkoma, NY), 10 EGTA (Sigma), $5 \mathrm{MgCl}_{2}$ (Sigma), 40 HEPES (Fluka), $2 \mathrm{Na}^{+}$-ATP (Sigma), $0.3 \mathrm{Na}^{+}$-GTP (Boehringer Mannheim, Indianapolis, IN), and 1 QX-314 (RBI, Natick, MA), with $0.3 \%$ neurobiotin (Vector); $\mathrm{pH}$ was adjusted to 7.25 with $1 \mathrm{M}$ $\mathrm{KOH}$. Spontaneous inward EPSCs were recorded at a holding potential of $-60 \mathrm{mV}$ with the same hardware and software as described above for sharp electrode intracellular recordings. Cells were used for analysis only if they had a stable holding current baseline, a stable series resistance of $<23 \mathrm{M} \Omega$ that varied by no more than $10 \%$ over the duration of the recording, and at least 50 discernable EPSCs during the recording. After recording, slices were fixed and stained (as described below), and cells were identified as RA projection neurons morphologically as described for sharp intracellular recordings.

Electrophysiology data analysis. Electrophysiological data were analyzed using custom LabVIEW analysis software written by Fred Livingston and Rob Neummann. Additional data analyses were performed with Origin software (Microcal, Northampton, MA), and statistical analyses were performed with JMP IN software (SAS Institute, Cary, NC). Distributions were tested for normality with the Shapiro-Wilk test; all comparisons involving distributions that were significantly $(p<0.05)$ non-normal were made using the nonparametric Mann-Whitney $U$ test. All comparisons between normal distributions were made with one-way ANOVAs (Student's $t$ tests), with variances assumed to be equal unless one of four tests (O'Brien, Brown-Forsythe, Levene, or Bartlett) showed significantly $(p<0.05)$ unequal variances. All values reported are means \pm SEM. For all statistical analyses, the relevant statistical tests and $n$ values are reported in the appropriate Tables and Figure legends, except for those comparisons not presented in Figures, for which these details are provided in the text.

The strength of the synaptic response evoked in RA by $\mathrm{HVc}$ fiber stimulation was estimated by measuring the onset slope of the rising phase of the EPSP, calculated within the first $2 \mathrm{msec}$ after the initial upward inflection from baseline. It has been shown previously that this initial component of the synaptic response of RA projection neurons to $\mathrm{HVc}$ fiber stimulation is a monosynaptic EPSP mediated predominantly by $A M P A$ receptors (Mooney and Konishi, 1991; Mooney, 1992) and thus is unlikely to be contaminated by any polysynaptic components of the response. Cells were hyperpolarized to $-90 \mathrm{mV}$ during stimulation to prevent action potential firing; instances in which the cell did fire an action potential before the falling phase of the EPSP were discarded from further analysis. EPSP slope values (in millivolts per millisecond) plotted against the stimulus amplitude (in microamperes) described a sigmoidal relationship, with an initial flat section reflecting subthreshold stimuli, a rising phase as EPSP slope increased with increasing stimulus amplitude above threshold, and an upper plateau, where the response was saturated. The rising phase was often best described by a combination of two different linear fits. Therefore, the slope of the relationship between the onset EPSP slope and stimulus amplitude for each cell was recorded as the average of the slopes of the two best linear fits of the data distribution between EPSP threshold and the plateau point. This slope (in (millivolts per millisecond per microamperes) is referred to as the stimulus- 
response function. The response threshold for each cell was determined by recording the lowest stimulus amplitude that elicited an EPSP.

For sharp electrode intracellular recordings, input resistances of RA projection neurons were calculated by injecting small $(-200 \mathrm{pA})$ hyperpolarizing current pulses throughout the recording session and measuring the resultant steady-state voltage change. In whole-cell voltage-clamp recordings, series resistance was monitored throughout the recording by measuring the current transients resulting from small $(-2 \mathrm{mV})$ hyperpolarizing voltage pulses. The reported input and series resistances are the average of all such measurements made while recording from each cell.

The current to firing frequency relationship was determined from the average instantaneous firing frequency over the first $0.5 \mathrm{sec}$ of a depolarizing current pulse. The calculated firing frequency was plotted as a function of the injected current amplitude, the resulting distribution fit linearly, and the slope, in hertz per nanoampere, reported to summarize the current-frequency relationship for the cell. The rate of spike frequency accommodation was measured by plotting the instantaneous firing frequency for each spike versus the interspike interval (ISI) number. This distribution was fit linearly, and the slope, in hertz per ISI, was used to describe the accommodation rate at that current injection amplitude, with a greater negative value indicative of a higher accommodation rate.

Spontaneous EPSC amplitude measurements were made from the whole-cell voltage-clamp continuous data records: EPSCs were detected and measured as deflections from the baseline holding current averaged over a $200 \mathrm{msec}$ window around each event. The detection threshold was adjusted manually throughout the data record to exclude noise but record the amplitude of all events that were clearly EPSCs (based on shape and time course). EPSC amplitude and frequency data for each cell were analyzed and plotted; EPSC amplitudes were then pooled for all cells across each treatment group, and the overall amplitude distributions and cumulative amplitude probability distributions were plotted. Cumulative amplitude probability distributions were compared statistically using the Kolmogorov-Smirnov goodness of fit test (Zar, 1996).

Histology of $R A$ projection neurons. After fixation (see above), slices were embedded in a solution of $30 \%$ egg albumin and $0.5 \%$ gelatin in $25 \mathrm{~mm}$ sodium phosphate buffer, hardened with $2 \%$ glutaraldehyde (all reagents from Sigma), and resectioned at $75 \mu \mathrm{m}$ on a vibratome (Series 1000 Model, Ted Pella). Neurobiotin was visualized by a standard avidin-HRP reaction using a 1:1000 dilution of the Vectastain ABC reagent (Vector Laboratories) in $25 \mathrm{~mm}$ PBS, followed by application of $0.05 \% 3^{\prime} 3^{\prime}$-diaminobenzidine tetrahydrochloride (DAB; Sigma) with $4.5 \times 10^{-4} \% \mathrm{H}_{2} \mathrm{O}_{2}$ (Mallinckrodt) in PBS, intensified with $0.027 \%$ $\mathrm{CoCl}_{2}$ and $0.02 \% \mathrm{NiSO}_{4}$ (Sigma).

$R A$ cell drawings and measurements of cellular morphology. Camera lucida drawings of neurobiotin-stained RA projection neurons were made on a Zeiss Axioskop using a $63 \times$ oil-immersion objective (numerical aperture 1.25). Only cells whose entire mediolateral extent was contained within the slice were drawn and analyzed: cells were selected only if there were no processes in either the medial- or lateral-most sections from a slice. Only well filled cells with clearly visible dendritic spines and extensive axon collaterals with clear synaptic bouton "swellings" were reconstructed. Reconstructions and anatomical measurements were made blind with regard to the age and treatment of the bird. After reconstruction, sections were counterstained with $0.1 \%$ cresyl violet (Sigma) to confirm RA's boundaries. Dendrites and axon collaterals were distinguished from one another based on their different diameters and spinous dendritic processes as compared with the smooth axons and axon collaterals. Spines were counted manually from the camera lucida drawings. Total length of dendrites and local axonal processes was measured for each cell from the drawing with a PlanWheel map measurer (Scalex). The complexity of dendritic and axonal processes was quantified by performing a Sholl analysis (Sholl, 1954). A grid representing a series of evenly spaced concentric circles of increasing radii in $20 \mu \mathrm{m}$ increments was placed over the camera lucida drawing and centered on the cell body, and the number of intersections between processes and each circle was counted. Two-way ANOVAs on Sholl distributions were used to make overall comparisons of process complexity across all radii; one-way ANOVAs were made between distributions at each individual radius to determine more specifically where, relative to the cell body (i.e., proximally or distally), such differences in process branching occurred. Drawings were digitally scanned and converted into Adobe Photoshop files (Adobe Systems, San Jose, CA). To measure the areas of the cell bodies, the edges of the largest cross section of each soma were traced and scanned, and the soma area was calculated using Scion Image software (Scion Corporation).

Statistical analyses on all morphological measurements were made using JMP IN software (SAS Institute). Distributions were tested for normality and compared statistically using the same tests (Mann-Whitney $U$ test, Student's $t$ test, as appropriate) as described for the analysis of electrophysiological data. All values reported are means \pm SEM.

LMAN lesions. Unilateral and bilateral LMAN lesions were made electrolytically in juvenile male birds between PHD 40 and 44. Birds were anesthetized with Equithesin [3-5 $\mu \mathrm{l} / \mathrm{gm}$ body mass; $1.05 \%$ pentobarbital (Abbott Laboratories, Chicago, IL), 4.25\% chloral hydrate (Sigma), $7 \%$ ethanol (AAPER, Shelbyville, KY), 36\% propylene glycol (Sigma), 2.1\% $\mathrm{MgSO}_{4}$ (Mallinckrodt)), which was supplemented with a subcutaneous scalp injection of lidocaine $(50 \mu \mathrm{l}, 2 \%$, Abbott Laboratories)]. The bird was placed in a stereotaxic device, the brain was exposed, and one to three lesions in LMAN were made per side, using stereotaxic coordinates from our own atlas, by passing current $(100 \mu \mathrm{A}$ for $90 \mathrm{sec}$, anodal) with a tungsten microelectrode (MicroProbe) connected to a Model A-360 Stimulus Isolator (World Precision Instruments, Sarasota, FL). After recovery from anesthesia, birds were returned to the colony.

All experiments on juvenile LMAN-lesioned birds were performed between 4 and $8 \mathrm{~d}$ after lesion, by which time the behavioral effects of the lesions on song, qualitatively similar to those described in the literature, were readily apparent (Bottjer et al., 1984) (J. M. Kittelberger, personal observations). When acute brain slices were prepared from LMANlesioned birds, several slices medial to slices containing RA were saved to confirm the extent of the lesion and were fixed immediately in $4 \%$ paraformaldehyde in $25 \mathrm{~mm}$ phosphate buffer for at least $12 \mathrm{hr}$. LMAN slices were resectioned at $100 \mu \mathrm{m}$ on a freezing microtome and stained with cresyl violet. Only lesions covering $75 \%$ or more of the volume of LMAN, and which included the complete dorsal and caudal portions of the nucleus (where the fibers projecting to RA leave the nucleus), were considered to be complete. In most cases it was impossible to find any intact portion of LMAN, which in control birds was visible in Nisslstained tissue as a distinct round region of larger cells in the anterior forebrain dorsal to the lamina medullaris dorsalis and area $\mathrm{X}$ and ventral to the lamina hyperstriatica (Bottjer et al., 1989).

In vivo biotinylated dextran amine injections to $H V c$. In 13 juvenile birds, PHD 40-42, and in 12 adult birds, >PHD 125, small injections of biotinylated dextran amine (BDA) [molecular weight 10,000; Molecular Probes] were placed bilaterally in HVc to label its axon terminals in RA. Borosilicate glass pipettes (Sutter Instruments) were prepared as for intracellular recording, but with the tips broken by $\sim 50 \mu \mathrm{m}$, and then filled with a $2 \%$ solution of BDA in PBS. Birds were prepared for surgery as described for LMAN lesions, and the pipette tip was positioned stereotaxically within HVc. BDA was delivered iontophoretically via a Stoelting model 51413 Precision Current Source (Stoelting, Wood Dale, IL), using $2 \mu \mathrm{A}$ of positive current for $5 \mathrm{~min}$ on a $50 \%$ duty cycle. Unilateral LMAN lesions (either right or left, selected randomly) were then made in these birds, as described above. Birds were deeply anesthetized with Equithesin 6-8 d later and perfused transcardially with $0.9 \%$ saline followed by $4 \%$ paraformaldehyde in $25 \mathrm{~mm}$ phosphate buffer. The brains were removed, post-fixed, and cryoprotected in $4 \%$ buffered paraformaldehyde with an ascending concentration of sucrose $(10,20$, and $30 \%)$ for $2-3 \mathrm{~d}$ at $4^{\circ} \mathrm{C}$. Brains were sectioned sagitally at 50 $\mu \mathrm{m}$ on a freezing microtome. Sections containing RA and $\mathrm{HVc}$ were reacted with avidin-HRP and DAB; more medial LMAN-containing sections were stained with cresyl violet to assess the completeness of the lesions, as described above.

BDA injections into $\mathrm{HVc}$ produced dense terminal labeling in RA. For each hemisphere, a single field of view was selected from the central-most portion of RA. All labeled axonal processes within the chosen field of view were drawn using a camera lucida on a Zeiss Axioskop with a $100 \times$ oil immersion objective (numerical aperture 1.4). Drawings were made blind with regard to whether the nucleus in question was from an LMAN-lesioned or -unlesioned hemisphere. Periodic swellings, which we assumed represented en passant synaptic boutons, were clearly visible along the labeled processes. Bouton frequency was calculated by counting all visible boutons within each field of view and dividing by the total length of axon collateral processes within the same field. 


\begin{tabular}{|c|c|c|c|c|c|c|}
\hline & Age, PHD & $\begin{array}{l}\text { Total spine } \\
\text { number }\end{array}$ & Spine density, $(\# / \mu \mathrm{m})$ & Soma area $\left(\mu \mathrm{m}^{2}\right)$ & $\begin{array}{l}\text { Total dendrite } \\
\text { length }(\mu \mathrm{m})\end{array}$ & $\begin{array}{l}\text { Total axon collateral } \\
\text { length }(\mu \mathrm{m})\end{array}$ \\
\hline $\begin{array}{l}\text { Fledgling } \\
\qquad(n=14-15)\end{array}$ & $\begin{array}{l}27.5 \pm 0.77 \\
(n=15)\end{array}$ & $\begin{array}{l}417 \pm 37 \\
(14)\end{array}$ & $\begin{array}{l}0.273 \pm 0.019 \\
(15)\end{array}$ & $\begin{array}{l}214 \pm 16 \\
(15)\end{array}$ & $\begin{array}{l}1559 \pm 89 \\
(14)\end{array}$ & $\begin{array}{l}913 \pm 90 \\
(14)\end{array}$ \\
\hline $\begin{array}{l}\text { Juvenile } \\
\qquad(n=15)\end{array}$ & $44.4 \pm 0.95$ & $\begin{array}{l}834 \pm 72 \\
* p<0.0001^{a}\end{array}$ & $\begin{array}{l}0.481 \pm 0.033 \\
*_{p}<0.0001^{b}\end{array}$ & $\begin{array}{l}301 \pm 20 \\
{ }^{*} p<0.002^{c}\end{array}$ & $1743 \pm 112$ & $\begin{array}{l}1829 \pm 150 \\
{ }^{*} p<0.0001^{a}\end{array}$ \\
\hline $\begin{array}{l}\text { Adult } \\
\qquad(n=13)\end{array}$ & $151.1 \pm 14.0$ & $\begin{array}{l}614 \pm 74 \\
* p<0.03^{a} \\
* * p<0.05^{c}\end{array}$ & $\begin{array}{l}0.388 \pm 0.053 \\
* p<0.04^{b} \\
* * p<0.03^{b}\end{array}$ & $253 \pm 19$ & $1612 \pm 116$ & $\begin{array}{l}1259 \pm 224 \\
* * p<0.04^{c}\end{array}$ \\
\hline $\begin{array}{l}\text { LMAN-lesioned juvenile } \\
\qquad(n=16)\end{array}$ & $46.6 \pm 0.49$ & $\begin{array}{l}611 \pm 82 \\
* * \boldsymbol{p}<\mathbf{0 . 0 5 2}^{c}\end{array}$ & $\begin{array}{l}\mathbf{0 . 3 5 5} \pm \mathbf{0 . 0 5} \\
* * p<0.05^{b}\end{array}$ & $\begin{array}{l}225 \pm 12 \\
* * p<0.003^{a}\end{array}$ & $1768 \pm 77$ & $1622 \pm 135$ \\
\hline
\end{tabular}

All values: mean \pm SEM. *Versus Fledgling; **versus juvenile; statistically significant differences in bold.

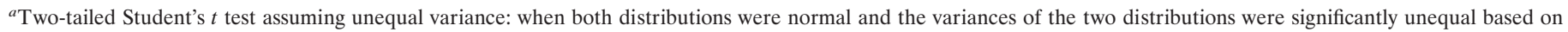
one or more of the O'Brien, Brown-Forsythe, Levene, and Bartlett tests.

${ }^{b}$ Mann-Whitney $U$ test: used when one or more of the distributions under comparison was significantly non-normal based on the Shapiro-Wilk test.

${ }^{c}$ Two-tailed Student's $t$ test assuming equal variance: used when both distributions were normal and their variances equal.

\section{RESULTS}

\section{Developmental changes in RA projection neuron morphology}

Initially, we used intracellular staining to characterize anatomical changes in RA projection neurons that occur during song development. These studies revealed marked changes in RA neuronal structure over development (Table 1; Figs. 1B, right side, 2). Between fledgling and juvenile ages, there was a $76 \%$ increase in spine density $(p<0.0001)$, a $100 \%$ increase in total spine number $(p<0.0001)$, a $100 \%$ increase in axon collateral length $(p<$ $0.0001)$, and a $41 \%$ increase in soma area $(p<0.002)$. Between the juvenile age and adulthood, spine density decreased by $19 \%$ $(p<0.03)$, total spine number decreased by $26 \%(p<0.05)$, and axon collateral length decreased by $31 \%(p<0.04)$. Despite these decreases, spine density and total spine number in adult RA projection neurons remained significantly higher than in fledglings, by $42 \%(p<0.04)$ and $47 \%(p<0.03)$, respectively. The soma size of adult RA projection neurons was not significantly different from either juvenile or fledgling measures, and adult axon collateral length did not differ significantly from that of fledgling birds. In addition, there was no evidence of any significant developmental change in total length of dendritic processes. Taken together, these results indicate that the juvenile RA projection neurons are structurally more robust and complex than at either earlier or later stages of development.

To gain a more detailed quantitative picture of changes in complexity of dendrites and axon collaterals, we performed a Sholl analysis (Sholl, 1954) on each cell. Two-way ANOVAs on the Sholl distributions (Fig. 2 legend) indicated that there was a significant increase in dendritic complexity of RA projection neurons between fledglings and juveniles $(p<0.05)$ that persisted into adulthood ( $p<0.03)$; one-way ANOVAs showed that this increase occurred specifically at 80, 100, and $120 \mu \mathrm{m}$ from the cell body (Fig. 2C). There was thus an early developmental increase in dendritic branching in the distal portion of the arbor, without any significant change in either the total length (see above) or the absolute radial extent of the arbor.

The overall complexity of the axon collateral arbors of RA projection neurons also increased significantly from fledgling to juvenile $(p<0.0001)$, but then decreased significantly by adulthood ( $p<0.001)$, although remaining significantly more complex than in fledglings $(p<0.03)$ (Fig. $2 D)$. Juvenile axon collateral arbors had significantly more intersections than fledgling arbors at all radii by one-way ANOVAs; those of adults had significantly fewer intersections than those of juveniles at 120 and $140 \mu \mathrm{m}$ radii; and there were no significant differences at any individual radius between adults and fledglings (Fig. 2D). Thus, the increase in total RA projection neuron axon collateral length and overall complexity that occurred between fledglings and juveniles occurred across the entire radial extent of the arbor, whereas the subsequent decrease in both total length and complexity between the juveniles and adults occurred mainly in the distal-most portion of the arbor, possibly reflecting retraction of some of the distal-most branches.

\section{Juvenile LMAN lesions: effects on RA projection neuron morphology}

Given that RA projection neurons are in a highly complex structural state at the same time that LMAN lesions exert their most disruptive behavioral effects on song development, we sought to examine whether lesioning LMAN, which is a major afferent to these neurons, perturbs their structure. We characterized the effects of juvenile LMAN lesions on the morphology of RA projection neurons (Table 1; Figs. $1 B$, left, 3). Electrolytic lesions of LMAN were made at PHD 40-42, when they have the most profound effects on song production (Bottjer et al., 1984). The birds were killed for RA projection neuron intracellular recording and cell fills between 4 and $7 \mathrm{~d}$ after lesion, by which point the LMAN axon terminals in RA have undergone significant degeneration (Herrmann and Arnold, 1991), and the abnormalities in song have emerged (Bottjer et al., 1984).

LMAN lesions induced rapid changes in the morphology of RA projection neurons. The most marked difference between normal juvenile and LMAN-lesioned juvenile RA projection neurons was a $26 \%$ decrease in spine density in the LMANlesioned population $(p<0.05$ ) (Table 1; Fig. $3 A$ ), which was similar in both magnitude and direction to the developmental change in spine density that occurs naturally between juvenile and adult birds. Camera lucida drawings of representative cells show the differences in spine density (Fig. $1 B$, left). In addition, RA projection neurons in LMAN-lesioned juveniles had $25 \%$ smaller cell body areas $(p<0.01)$ (Fig. $3 A)$, as well as altered axonal structure (Fig. 3D). There was no effect of juvenile LMAN 

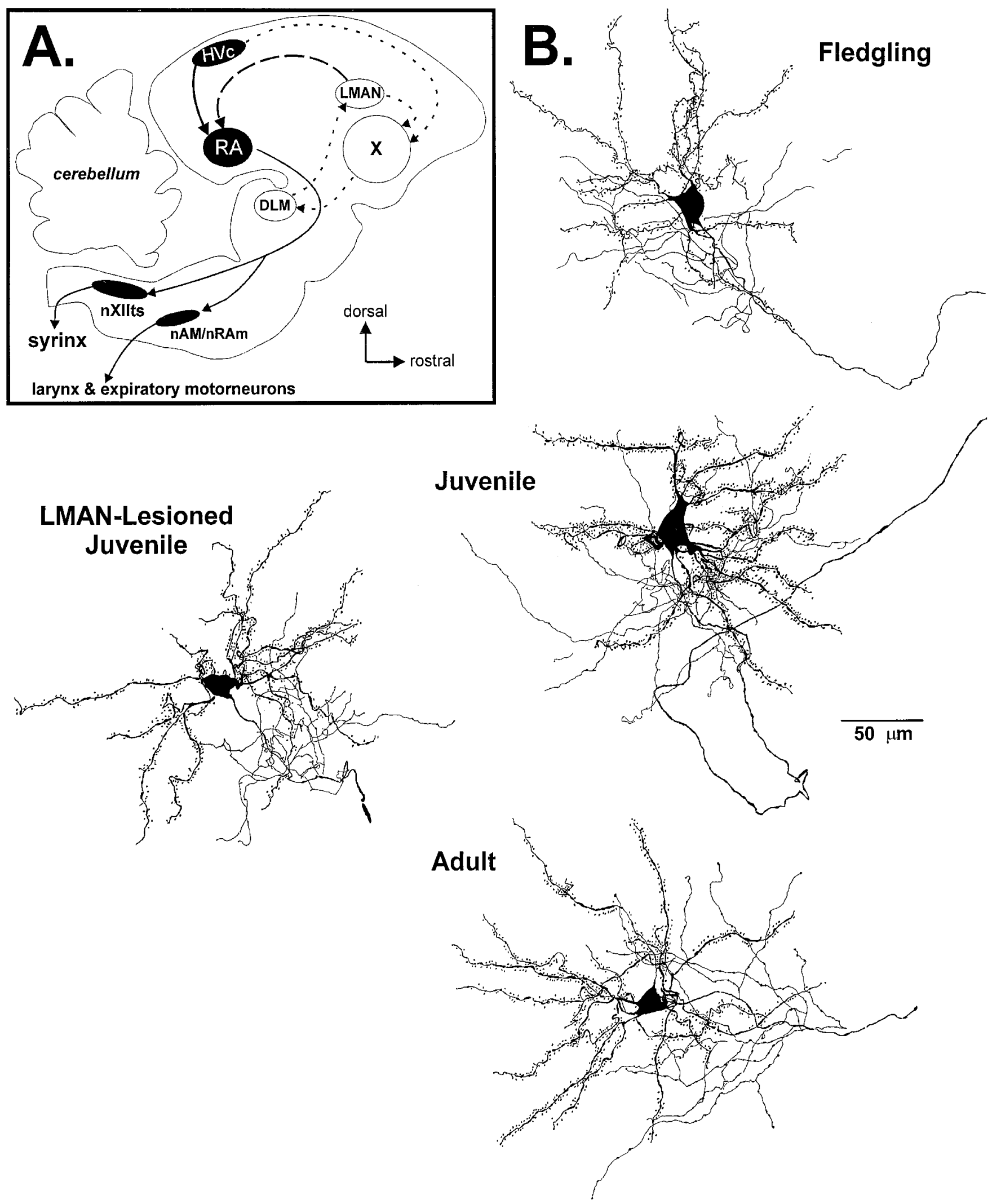

Figure 1. A, A simplified schematic diagram of the brain nuclei that constitute the avian song system (sagittal view). The vocal motor pathway (black) includes (in descending order) the nucleus HVc (used here as a proper name), the robust nucleus of the archistriatum $(R A)$, the tracheosyringeal portion of the hypoglossal nucleus ( $n X I I t s)$, the nucleus ambiguus $(n A M)$, the nucleus retroambigualis ( $n R A m)$ (Nottebohm et al., 1976, 1982; Vicario, 1993; Wild, 1993a,b), and the musculature of the syrinx (the main vocal organ), larynx, and respiratory apparatus (Nottebohm et al., 1976; Wild, 1993a,b). Lesions of any of these nuclei disrupt the production of learned song (Nottebohm et al., 1976; Simpson and Vicario, 1990), and chronic recording experiments have shown premotor activity preceding the onset of song in $\mathrm{HVc}$ and RA (McCasland, 1987; (Figure legend continues) 

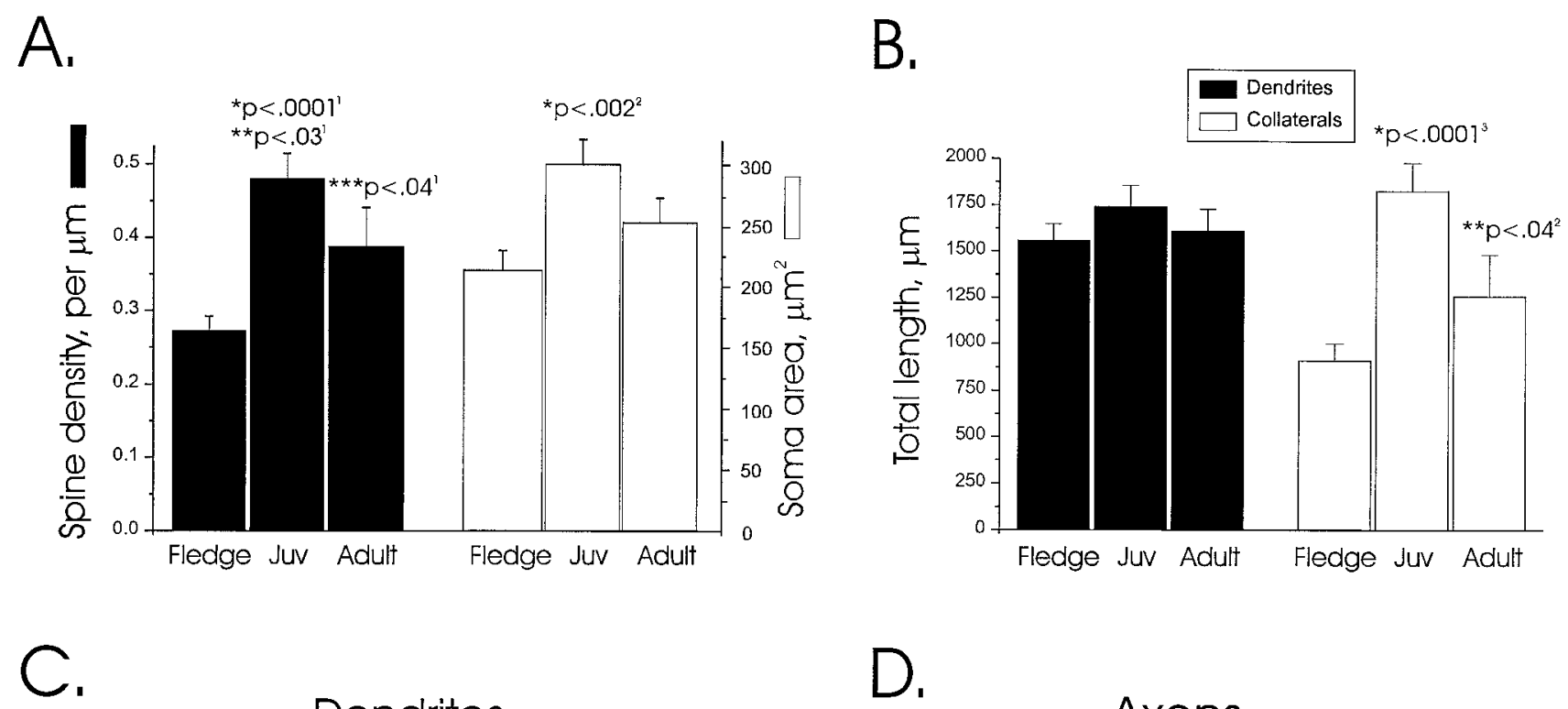

\section{Dendrites}

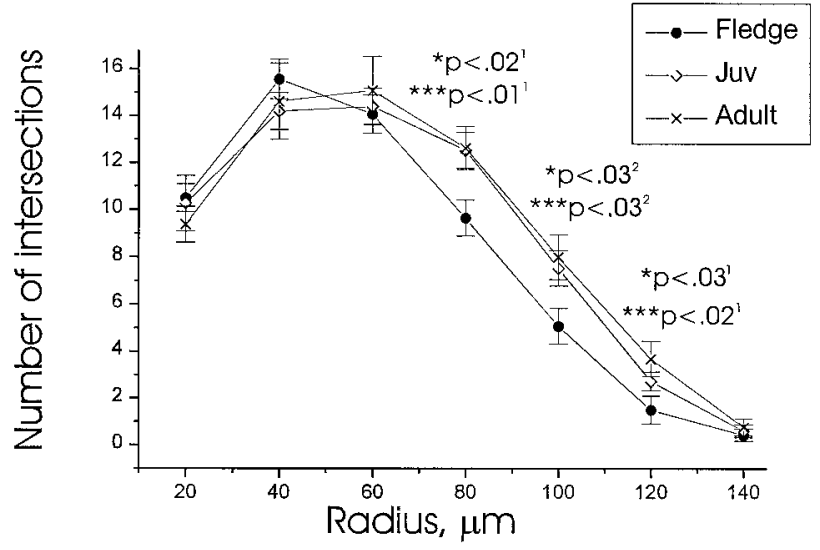

D.

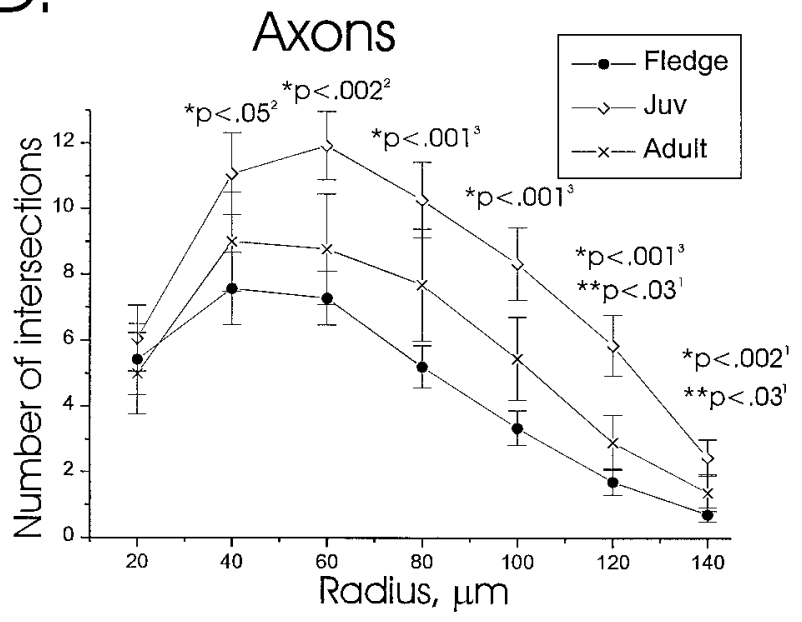

Figure 2. The morphology of RA projection neurons changed markedly over development, and juvenile cells were larger and more complex than their fledgling and adult counterparts. $A$, Dendritic spine densities (black) were significantly higher in juvenile RA projection cells than in fledglings $\left(~ p<.001^{l}\right)$ or adults $\left(p<.03^{l}\right)$, and whereas adult spine density remained higher than in fledglings $\left(p<.04^{I}\right)$. The soma areas (white) of juvenile RA neurons were larger than those of fledglings $\left(p<.002^{2}\right)$. B. The total dendritic length of RA projection neurons (black) was quite stable over development, in contrast to the total length of their local axon collaterals, which doubled between fledgling and juvenile times $\left(p<.0001^{3}\right)$ and then declined by approximately one-third by adulthood $\left(p<.04^{2}\right)$. $C$, Sholl analysis indicated that the more distal dendritic arbor (i.e., $80-120 \mu \mathrm{m}$ from the cell body) increased in complexity (i.e., number of intersections) between fledgling and juvenile times; these differences are maintained in the adult. Two-way ANOVAs confirmed this result: there was a significant overall effect of age on number of dendritic intersections between fledglings and juveniles [p $<0.05$; there was also a significant $(p<0.05)$ interaction between age and radius] and between fledglings and adults $(p<0.03)$, but not between juveniles and adults. $D$, A similar analysis of axon collateral complexity showed that juvenile RA cells had more complex local collaterals than their fledgling or adult counterparts. The increase in complexity from fledglings to juveniles occurred across the entire extent of the axon collateral arbor (40-140 $\mu \mathrm{m})$, but the decrease between juveniles and adults was found only in the distal-most portion of the arbor $(120-140 \mu \mathrm{m})$. Two-way ANOVAs showed that age had a significant overall effect on collateral intersections between juveniles and both fledglings $(p<0.0001)$ and adults $(p<0.001)$. There were no significant differences in local axonal complexity between adults and fledglings at any individual radius, but a two-way ANOVA did show an overall effect of age $(p<0.03)$, suggesting that adult RA projection neurons retained somewhat higher local collateral complexity than in fledglings. Statistically significant $p$ values: *juvenile (Juv) versus fledgling (Fledge); **juvenile versus adult (Adult); ***adult versus fledgling. Statistical tests: ${ }^{1}$ Mann-Whitney $U$ test $(1$ or more of the distributions was significantly non-normal by the Shapiro-Wilk test); ${ }^{2}$ two-tailed Student's $t$ test assuming equal variance (both distributions normal); ${ }^{3}$ two-tailed Student's $t$ test assuming unequal variance (both distributions normal; variances significantly unequal by one or more of the O'Brien, Brown-Forsythe, Levene, or Bartlett tests). Fledgling: $n=15$ cells from eight birds for spine density and soma distributions, 14 cells from eight birds for all dendrite and axon collateral comparisons. Juvenile: $n=15$ cells from nine birds; adult: $n=13$ cells from nine birds.

$\mathrm{Yu}$ and Margoliash, 1996). The anterior forebrain pathway (open symbols, dashed arrows) is critical for normal song development and consists of area $X$, the medial nucleus of the dorsolateral thalamus $(D L M)$, and the lateral magnocellular nucleus of the anterior neostriatum $(L M A N)(\mathrm{Okuhata}$ and Saito, 1987; Bottjer et al., 1989). The primary input to the anterior forebrain pathway is from HVc to area $X$; the sole output of LMAN to the vocal motor pathway is onto RA. B, Camera lucida drawings of representative RA projection neurons at the three developmental stages studied here (fledgling, juvenile, and adult, on the right), as well in LMAN-lesioned juveniles (left), show the increased dendritic spine density of the normal juvenile cells relative to other ages and treatments. The spine densities of the two juvenile cells shown here are marked by arrows in Figure $3 B$. 
A.

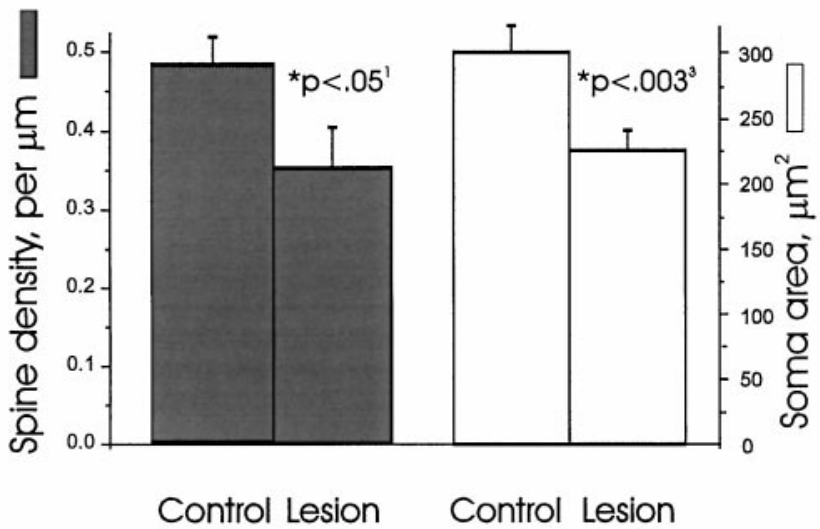

C.

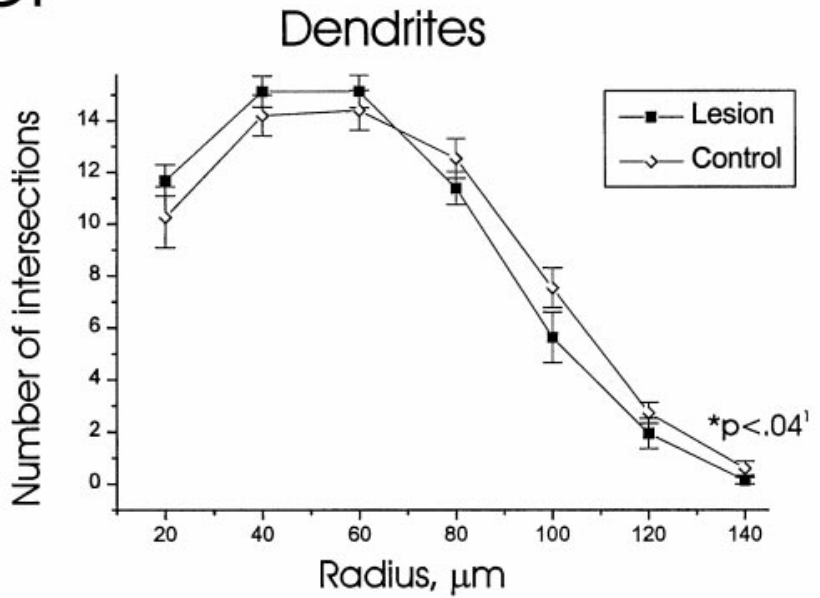

B.

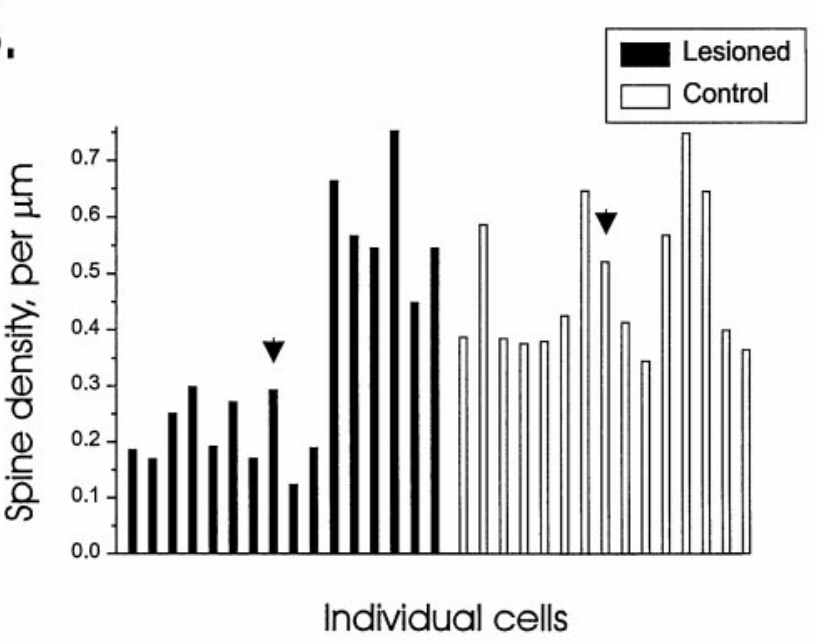

D.

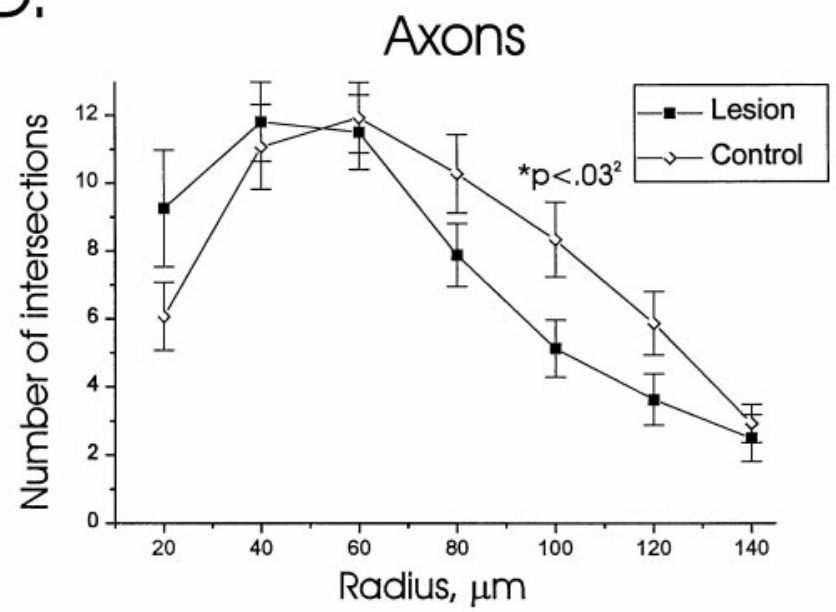

Figure 3. Juvenile LMAN lesions induced rapid morphological changes in RA projection neurons. A, The dendritic spine density ( gray) and soma area (white) of RA neurons in LMAN-lesioned juvenile birds was lower than in age-matched controls (lesions were made 4-7 d before data collection). $B$, The dendritic spine densities of RA neurons from juvenile birds with LMAN lesions (black bars) fell into two distinct classes, one much lower than those of control cells (open bars), and another population that was indistinguishable from control values. The individual cells are presented in random order along the $x$-axis, except that cells from lesioned and control birds, as well as the higher and lower spine density classes of cells from lesioned birds, are grouped separately. The spine density distribution in lesioned birds was significantly non-normal $(p<0.04$, Shapiro-Wilk test). Arrows mark values obtained from the two juvenile RA projection cells depicted in Figure $1 B$. $C$, The dendritic complexity of juvenile RA projection neurons was not significantly altered by LMAN lesions, except at the most distal point measured (140 $\mu \mathrm{m}$ from the cell body). A two-way ANOVA showed no overall effect of LMAN lesions on dendritic intersections. $D$, The local axon collateral complexity was lower in lesioned animals, with a significant reduction at the $100 \mu \mathrm{m}$ radius. In addition, a two-way ANOVA showed a significant $(p<0.05)$ interaction between lesioning and radius on collateral intersections; i.e., LMAN lesions influenced where radially the axon collaterals tend to occur, with fewer branches in the distal portion of the arbor in lesioned birds. Statistical tests: ${ }^{1}$ Mann-Whitney $U$ test; ${ }^{2}$ two-tailed Student's $t$ test assuming equal variance; ${ }^{3}$ two-tailed Student's $t$ test assuming unequal variance. LMAN-lesioned juveniles: $n=16$ cells from eight birds; control juveniles: $n=15$ cells from nine birds.

lesions on total axon collateral length (Table 1), but Sholl analysis did reveal a significant ( $p<0.05$; two-way ANOVA) interaction between lesioning and radius affecting collateral complexity, as well as a significant decrease after lesions in axon collateral intersections at the $100 \mu \mathrm{m}$ radius (Fig. $3 D$ ). In contrast, there was no difference between normal and LMAN-lesioned RA projection neuron dendritic arbors in either total length (Table 1) or overall complexity (by two-way ANOVA) (Fig. 3C) and only a very slight but significant reduction in number of dendrite intersections at $140 \mu \mathrm{m}$ radius (Fig. $3 C$ ). In summary, LMAN lesions had marked effects on RA projection neuron dendritic spine density and soma size and on the complexity of local collateral arbors.
The effects of juvenile LMAN lesions on RA projection neuron spine density may not have been homogeneous. The distribution of spine densities in LMAN-lesioned cells was non-normal $(p<0.04$, Shapiro-Wilk test) and appeared distinctly bimodal (Fig. $3 B$ ), with two nonoverlapping subpopulations. One population ( $n=10$ cells from seven birds) had an average spine density of $0.215 \pm 0.019$ spines per micrometer $(55 \%$ less than the average spine density of normal juveniles; $p<0.0001$, MannWhitney $U$ test), with a range of $0.124-0.299$, which did not overlap with the range of spine densities in normal juveniles (0.346-0.751). A second population of R A projection neurons in LMAN-lesioned juveniles ( $n=6$ cells from five birds) had an average spine density of $0.588 \pm 0.043$ spines per micrometer, 
which was not different from the average spine density of normal juvenile cells ( $p>0.07$, Mann-Whitney $U$ test), and had a range (0.45-0.754) overlapping in its entire extent with the range of spine densities found in normal juveniles. Whether a particular cell was in the high or low spine density population did not correlate with the extent or location of the LMAN lesion, with the location of the cell within RA, or with the degree to which the bird's song was affected by the lesion. In fact, on four occasions, cells of both high and low spine density were found in the same bird; on two occasions cells of both high and low spine density were found in the same hemisphere in the same bird. Because axon collateral length was very sensitive to fill quality, and to ensure that these different populations of RA neurons did not merely reflect filling artifacts, we also compared axon collateral length between the two groups and found no significant difference ( $p>0.40$, Student's $t$ test, equal variance). Furthermore, there was no significant correlation between spine density and axon collateral length in any of the experimental groups (Spearman's rho tests). Because soma area was also reduced in LMANlesioned juveniles, we tested whether the bimodality of the spine density distribution correlated with a similar bimodality in soma area. The soma area distribution of LMAN-lesioned cells was normal ( $p>0.6$, Shapiro-Wilk test), showing no evidence of bimodality. There was no difference in soma area between the high and low spine density subpopulations of cells $(p>0.3$, Student's $t$ test, equal variance) and no correlation between spine density and soma area among LMAN-lesioned cells $(p>0.7$, Spearman's rho test). These analyses suggest that in the LMANlesioned birds there may have been one population of RA projection neurons in which spine density was dramatically affected and another population in which this feature was unaffected, at least at this time after the lesion.

\section{HVc terminal bouton frequency: developmental and LMAN-lesion effects in juveniles and adults}

Other studies have shown that the vast majority of inputs onto RA projection neurons' spines are made by HVc axons and local RA collaterals (Canady et al., 1988; Herrmann and Arnold, 1991). Given that juvenile LMAN lesions affect RA dendritic spines and local axon collateral complexity, we wanted to test whether such lesions also altered $\mathrm{HVc}$ axon terminals within RA. Therefore, we made extracellular injections of BDA into $\mathrm{HVc}$ in both control and LMAN-lesioned hemispheres of juvenile (PHD $40-43$ ) birds. Birds were allowed to survive for $6-8$ d to allow both the effects of the unilateral LMAN lesions and the complete transport of the tracer to occur. In seven birds, complete unilateral LMAN lesions were made, and terminal labeling (dense fibers with clear swellings assumed to be synaptic boutons) was obtained on both sides, allowing for internal comparison within each bird between the control and lesioned hemispheres. In all seven of these birds the bouton frequency on HVc axon arbors in RA was lower on the LMAN-lesioned side (Fig. 4). The decrease in bouton frequency from control to LMAN-lesioned sides ranged from 6 to $32 \%$, with an average decrease of $17 \%(p<$ $0.02)$. There was no difference in total length of labeled axon collaterals between lesioned and control hemispheres. Thus, juvenile LMAN lesions cause alterations not only in the complexity of the local axon collaterals of RA projection neurons but also in the frequency of synaptic specializations made by $\mathrm{HVc}$ axon terminals within RA.

LMAN lesions in normal adult birds, unlike those in juvenile birds, have no obvious effects on song. To test whether the effects

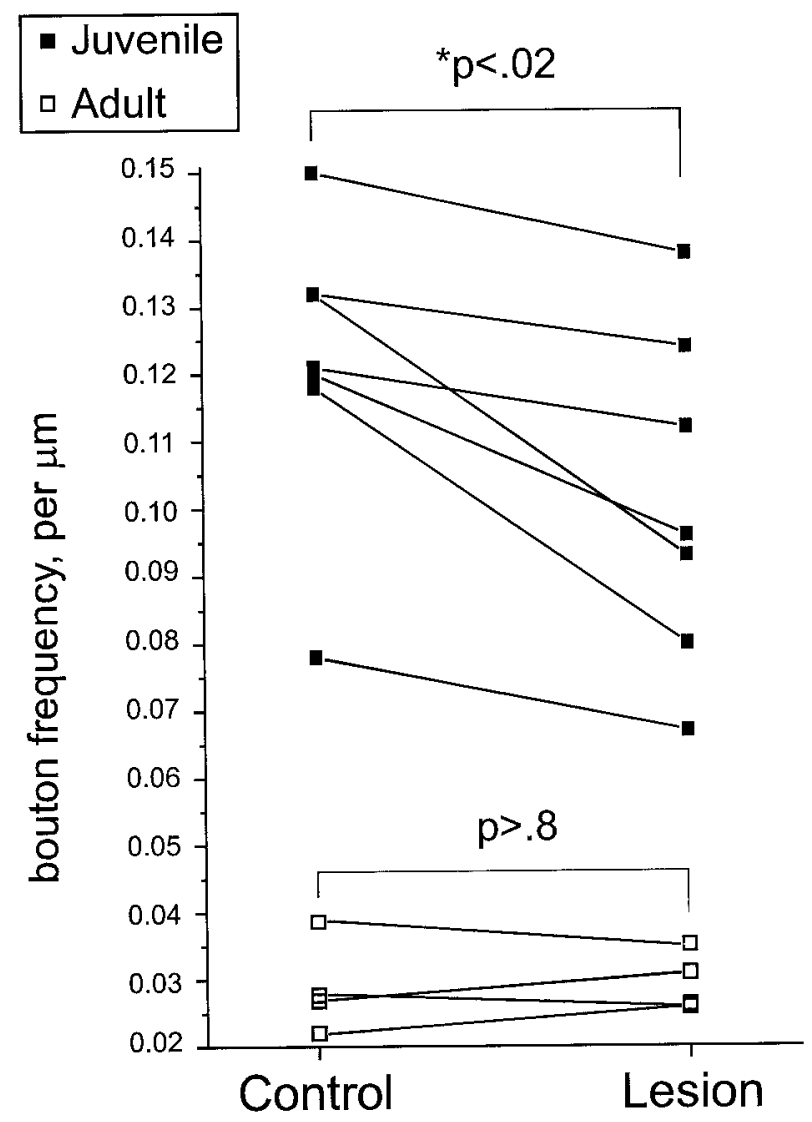

Figure 4. Juvenile, but not adult, LMAN lesions reduced HVc axon terminal bouton frequency in RA. Linear bouton frequency in RA was measured (in number of boutons per micrometer of axon collateral length) after unilateral lesion of LMAN and bilateral tracer injection into HVc (see Materials and Methods). In juveniles ( $\square$ ), between-hemisphere, within-bird comparisons revealed consistently lower bouton frequency in $\mathrm{RA}$ on the side receiving the LMAN lesion ( $p<0.02$, paired $t$ test, $n=$ 7 birds). In adults ( $\square$ ), on the other hand, lesions did not affect $\mathrm{HVc}$ bouton frequency in RA ( $p>0.8$, paired $t$ test, $n=4$ birds), which was higher on the lesioned side just as often as it was lower.

of LMAN lesions on HVc-RA terminal arbor bouton frequency correlate with the behavioral effects of these lesions, we examined this parameter in adult LMAN-lesioned birds. Employing the same experimental procedure used in juvenile birds, we obtained four adult birds in which we could make internal comparisons of $\mathrm{HVc}$ terminal arbor bouton frequency in RA between LMANlesioned and control hemispheres. Adult LMAN lesions had no effect on HVc bouton frequency within RA (Fig. 4) $(p>0.8)$. In fact, bouton frequency on the lesioned side was higher in two of the four birds, in stark contrast to the results obtained in juveniles, where all birds had reduced bouton frequency on the lesioned side. We also made an unpaired comparison of mean $\mathrm{HVc}$ bouton frequency among all LMAN-lesioned $(n=6)$ and control $(n=7)$ hemispheres in which there was good $\mathrm{HVc}$ terminal labeling, which showed no difference between LMANlesioned and control hemispheres in adult birds $(0.032 \pm 0.003$ vs $0.033 \pm 0.003$ boutons per micrometer; $p>0.85$, two-tailed Student's $t$ test assuming equal variance). Unlike juvenile LMAN lesions, adult LMAN lesions have no effect on the frequency of HVc synaptic boutons within RA.

Finally, these adult injections allowed us to make a developmental comparison of $\mathrm{HVc}$ bouton frequency in RA between 


\begin{tabular}{|c|c|c|c|c|c|c|c|c|c|}
\hline & $\begin{array}{l}\text { Stimulus- } \\
\text { response } \\
\text { function } \\
\left(\mathrm{mV} \cdot \mathrm{msec}^{-1} \cdot\right. \\
\left.\mu \mathrm{A}^{-1}\right)\end{array}$ & $\begin{array}{l}\text { Response } \\
\text { threshold } \\
(\mu \mathrm{A})\end{array}$ & $\begin{array}{l}\mathrm{R}_{\text {Input }} \\
(\mathrm{M} \Omega)\end{array}$ & $\begin{array}{l}\text { Baseline } \\
\text { firing rate } \\
(\mathrm{Hz})\end{array}$ & $\begin{array}{l}\text { Current- } \\
\text { frequency } \\
\text { relation } \\
(\mathrm{Hz} / \mathrm{nA})\end{array}$ & $\begin{array}{l}\text { Accommoda- } \\
\text { tion rate } \\
(@ 400 \mathrm{pA}, \\
\mathrm{Hz} / \mathrm{ISI})\end{array}$ & $\begin{array}{l}\text { Spontaneous } \\
\text { EPSC amplitude } \\
(<30 \mathrm{pA}), \mathrm{pA}\end{array}$ & $\begin{array}{l}\text { Spontane- } \\
\text { ous EPSC } \\
\text { frequency } \\
(\mathrm{Hz})\end{array}$ & $\begin{array}{l}R_{\text {Series }} \\
(\mathrm{M} \Omega)\end{array}$ \\
\hline Fledgling & & & $\begin{array}{l}89 \pm 14 \\
(n=7)\end{array}$ & $\begin{array}{l}9.2 \\
(1)\end{array}$ & $\begin{array}{l}54.7 \pm 7.3 \\
(6)\end{array}$ & $\begin{array}{l}-0.93 \pm 0.13 \\
(4)\end{array}$ & & & \\
\hline Juvenile & $\begin{array}{l}0.070 \pm 0.017 \\
(n=12)\end{array}$ & $\begin{array}{l}217 \pm 51 \\
(12)\end{array}$ & $\begin{array}{l}86 \pm 7 \\
(21)\end{array}$ & $\begin{array}{l}12.0 \pm 0.8 \\
(13)\end{array}$ & $\begin{array}{l}67.3 \pm 3.5 \\
(23)\end{array}$ & $\begin{array}{l}-0.44 \pm 0.05 \\
* p<0.01^{a} \\
(18)\end{array}$ & $\begin{array}{l}8.9 \pm 0.1 \\
(2013 \text { events } \\
\quad \text { from } 14 \text { cells })\end{array}$ & $\begin{array}{l}0.27 \pm 0.06 \\
(13)\end{array}$ & $\begin{array}{l}20.8 \pm 0.5 \\
(13)\end{array}$ \\
\hline Adult & $\begin{array}{l}\mathbf{0 . 1 7 8} \pm \mathbf{0 . 0 5 1} \\
* * \boldsymbol{p}<\mathbf{0 . 0 5}^{\boldsymbol{a}} \\
(n=8)\end{array}$ & $\begin{array}{l}\mathbf{5 8} \pm \mathbf{1 6} \\
* * p<\mathbf{0 . 0 2}^{a} \\
(8)\end{array}$ & $\begin{array}{l}91 \pm 15 \\
(9)\end{array}$ & $\begin{array}{l}15.3 \pm 2.0 \\
(9)\end{array}$ & $\begin{array}{l}\mathbf{7 0 . 8} \pm \mathbf{3 . 4} \\
* p<\mathbf{0 . 0 4}{ }^{b} \\
(19)\end{array}$ & $\begin{array}{l}-0.39 \pm 0.06 \\
* p<0^{a} 01^{a} \\
(14)\end{array}$ & & & \\
\hline $\begin{array}{l}\text { LMAN-lesioned } \\
\text { juvenile }\end{array}$ & $\begin{array}{l}\mathbf{0 . 1 6 9} \pm \mathbf{0 . 0 3 5} \\
*{ }^{*}<\mathbf{0 . 0 1}^{\boldsymbol{a}} \\
(n=13)\end{array}$ & $\begin{array}{l}85 \pm 20 \\
* * p<0.04^{a} \\
(13)\end{array}$ & $\begin{array}{l}82 \pm 7 \\
(18)\end{array}$ & $\begin{array}{l}11.7 \pm 0.6 \\
\text { (9) }\end{array}$ & $\begin{array}{l}70.9 \pm 4.5 \\
(19)\end{array}$ & $\begin{array}{l}-0.50 \pm 0.08 \\
(18)\end{array}$ & $\begin{array}{l}\mathbf{9 . 8} \pm \mathbf{0 . 1} \\
* * \boldsymbol{p}<\mathbf{0 . 0 0 0 1}^{\boldsymbol{a}} \\
(1692 \text { events } \\
\text { from } 8 \text { cells })\end{array}$ & $\begin{array}{l}0.32 \pm 0.12 \\
\text { (7) }\end{array}$ & $\begin{array}{l}21.1 \pm 0.5 \\
\text { (7) }\end{array}$ \\
\hline
\end{tabular}

All values: mean \pm SEM. *Versus fledgling; **versus juvenile control; statistically significant differences in bold.

${ }^{a}$ Mann-Whitney $U$ test: used when one or more of the distributions under comparison was significantly non-normal based on the Shapiro-Wilk test.

${ }^{b}$ Two-tailed Student's $t$ test assuming equal variance: used when both distributions were normal and their variances equal.

juveniles and adults. Adult control RAs $(n=7)$ had a $74 \%$ lower mean bouton frequency $(0.033 \pm 0.003$ boutons per micrometer $)$ than did juvenile control RAs $(0.124 \pm 0.008$ boutons per micrometer; $n=8 ; p<0.0001$, two-tailed Student's $t$ test assuming unequal variance). Thus, there is a developmental as well as a juvenile LMAN-lesion induced decline in the frequency of synaptic boutons on $\mathrm{HVc}$ axons within RA.

\section{Electrophysiology of RA projection neurons: developmental and LMAN lesion effects}

The morphological changes in RA projection neuron dendritic spines and $\mathrm{HVc}$ axon terminal boutons suggested that juvenile LMAN lesions might affect the function of the $\mathrm{HVc}$ to RA synapse. To directly test whether the structural changes in RA synaptic contacts after LMAN lesions result in functional changes in synaptic transmission between $\mathrm{HVc}$ and $\mathrm{RA}$, we examined the strength of connectivity between $\mathrm{HVc}$ and RA electrophysiologically. To do so, we measured, for each cell, the rate of increase of the initial slope of the evoked EPSP as a function of increasing stimulus amplitude (which we refer to as the stimulus-response function; see Materials and Methods). LMAN lesions affected this functional parameter: the average stimulus-response function in juvenile LMAN-lesioned birds was $141 \%$ steeper than in normal juveniles $(p<0.01)$ (Table 2; Fig. $5)$. This difference is notably similar in both magnitude and direction to the normal developmental change in stimulus-response function in RA projection neurons between juveniles and adults: adult cells had a $154 \%$ steeper stimulus-response function than normal juvenile cells $(p<0.05)$. In addition, we found that the stimulus amplitude threshold required to evoke a response in RA projection neurons in normal juveniles was higher than in both LMAN-lesioned juveniles (by 156\%, $p<0.04$ ) and adults (by $277 \%, p<0.02$ ) (Table 2). These data show a steeper synaptic stimulus-response relationship at the $\mathrm{HVc}$ to $\mathrm{RA}$ synapse in LMAN-lesioned juveniles and normal adults, suggesting that the morphological changes that occur in RA both immediately after juvenile LMAN lesions and over normal development are paral- leled by functional changes in synaptic transmission between $\mathrm{HVc}$ and RA.

We wanted to know whether LMAN lesions also had significant effects on the general intrinsic electrophysiological properties of RA projection neurons or whether the effects of the lesions were specific to synaptic transmission. Thus, we measured and analyzed several intrinsic parameters of RA projection neuron electrophysiology in control and LMAN-lesioned juvenile birds as well as in fledglings and adults (Table 2). No significant differences were detected in input resistance measurements between any of the various age and treatment groups (Table 2). Likewise, there were no significant differences in the baseline firing rate of any of the different RA cell groups, which were all tonically active at $\sim 10-15 \mathrm{~Hz}$ (Table 2 ). Firing frequency in these cells is known to increase linearly with injected current (Mooney, 1992). To analyze the relationship between injected current and spike frequency, we plotted the mean instantaneous spike frequency separately for each cell as a function of the amplitude of the injected current, created a linear fit to the data, and recorded the slope of this line (in hertz per nanoampere) as the currentfrequency relationship for the cell. The current-frequency relationship distributions were compared statistically between age and treatment groups (Table 2). The only significant difference detected was a $32 \%$ higher current-frequency relationship in adult $\mathrm{RA}$ projection neurons than in those of fledglings $(p<$ 0.04). We also examined the spike frequency accommodation rates for $\mathrm{RA}$ projection neurons at a current injection amplitude of $400 \mathrm{pA}$ (Table 2). RA projection neurons in fledgling birds had a steeper rate of spike frequency accommodation at $400 \mathrm{pA}$ than in both juveniles and adults, by $111 \%(p<0.006)$ and $138 \%(p<$ $0.01)$. Thus, as RA projection neurons mature, they exhibit both a steeper current-frequency relationship and reduced spike frequency accommodation. Lesioning LMAN, however, has no effect on these parameters. In fact, RA projection neurons in LMAN-lesioned birds are normal, as compared with agematched controls, in all of the measures of intrinsic physiology examined here (Table 2). The electrophysiological effects of 

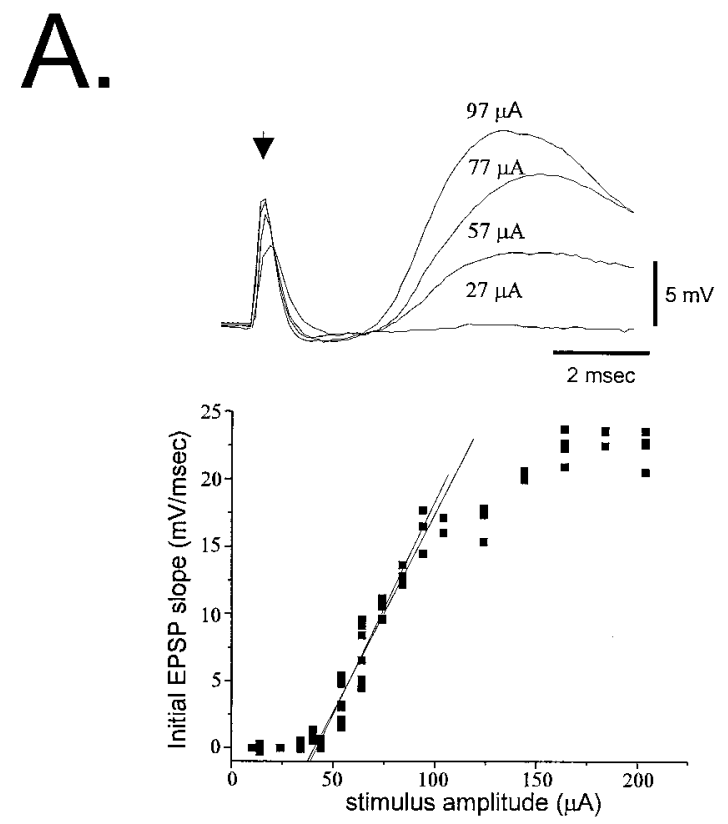

C.

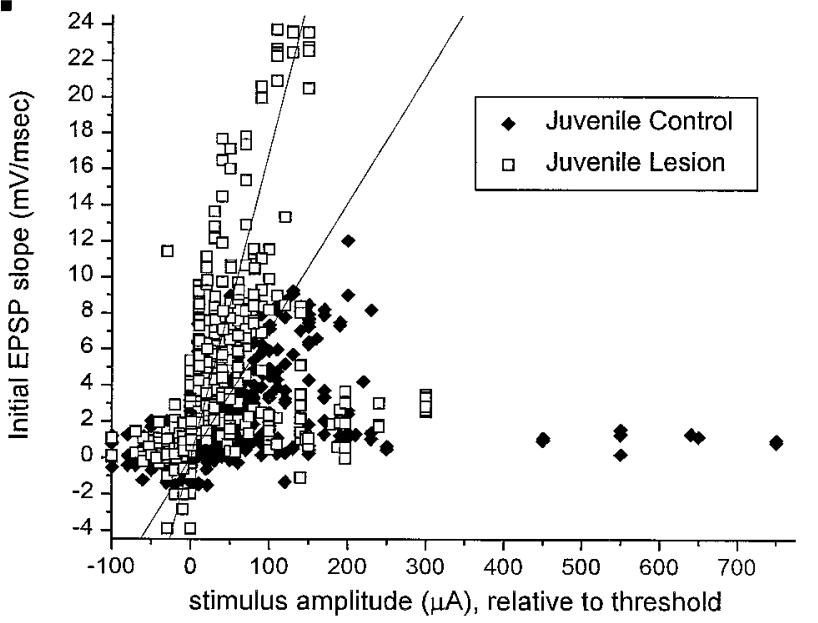

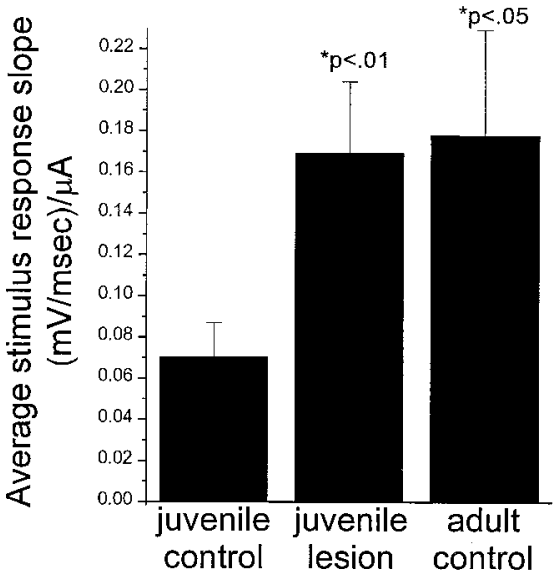

D.

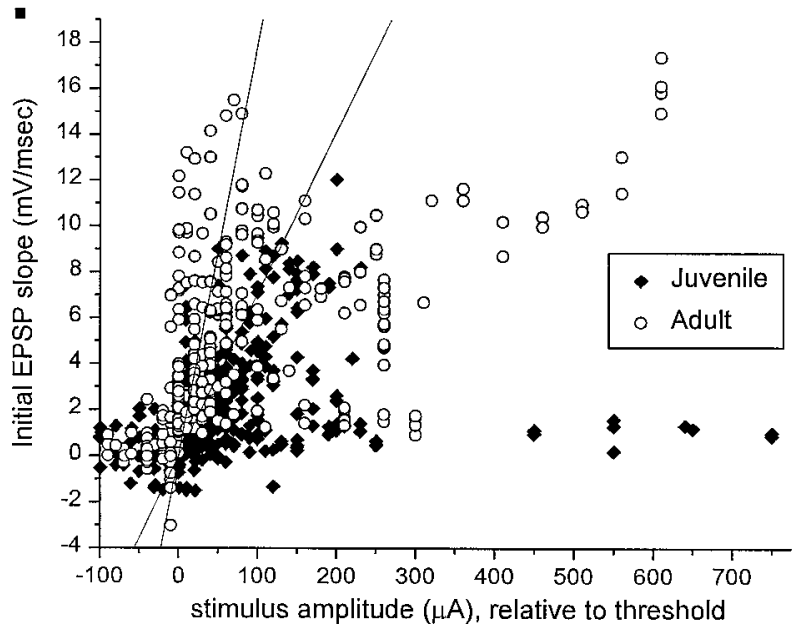

Figure 5. The stimulus-response relationship of EPSPs evoked in RA by electrical stimulation of HVc fibers in brain slices changed both with development and after LMAN lesions. A, The onset slope and amplitude of EPSPs evoked in an adult RA projection neuron (top traces) by HVc fiber stimulation (at point marked by arrow) increased as a function of current amplitude (stimulus levels are shown above each trace). Currents above $40 \mu \mathrm{A}$ evoked an EPSP from this RA projection neuron; higher currents elicited increasingly larger EPSPs, with steeper onset slopes. At even higher stimulus intensities, these EPSPs triggered action potentials, distinguishing them as excitatory (data not shown). Measurements of the initial slope of the EPSP at different stimulus currents were used to plot the stimulus-response relationship for this cell (bottom graph), for which the two best linear fits of the stimulus-response data are superimposed (see Materials and Methods). $B$, The average stimulus-response relationship (i.e., the mean of the two best linear fits of the stimulus-response data) is shown for HVc EPSPs recorded from RA projection neurons in juvenile control animals $(n=12$ cells from 4 birds), juveniles with LMAN lesions ( $n=13$ cells from 5 birds), and adults $(n=8$ cells from 3 birds). The stimulus-response relationship was significantly steeper both in juveniles receiving LMAN lesions $(p<0.01)$ and in adults $(p<0.05)$, relative to control juveniles $($ Mann-Whitney $U$ test). $C, D$, Stimulus-response plots show all of the individual EPSP slope measurements made from each cell in juvenile control slices $(C, D)$, juveniles with LMAN lesions $(C)$, and adults $(D)$. Responses are plotted against stimulation current normalized to threshold, i.e., the absolute current minus the minimum current needed to evoke an EPSP for a given cell. A line depicting the average stimulus-response relationship for each cell class is superimposed on these individual points. Note that the juvenile control cells yield many slope measurements with a shallower relationship to the stimulus current than was seen in cells from juveniles with LMAN lesions or adults.

LMAN lesions on these cells that we can detect therefore appear to be restricted to effects on synaptic transmission.

\section{Spontaneous EPSC amplitudes}

To further characterize the changes in synaptic transmission induced in RA projection neurons by juvenile LMAN lesions, we examined spontaneous synaptic currents recorded in whole-cell voltage-clamp mode $\left(V_{\mathrm{h}}=-60 \mathrm{mV}\right)$ in RA projection neurons in brain slices made from juvenile birds that had previously received unilateral LMAN lesions. To isolate EPSCs, we recorded in picrotoxin $(50 \mu \mathrm{M})$. Spontaneous EPSCs were readily detectable in RA neurons from both control and lesioned hemispheres. 

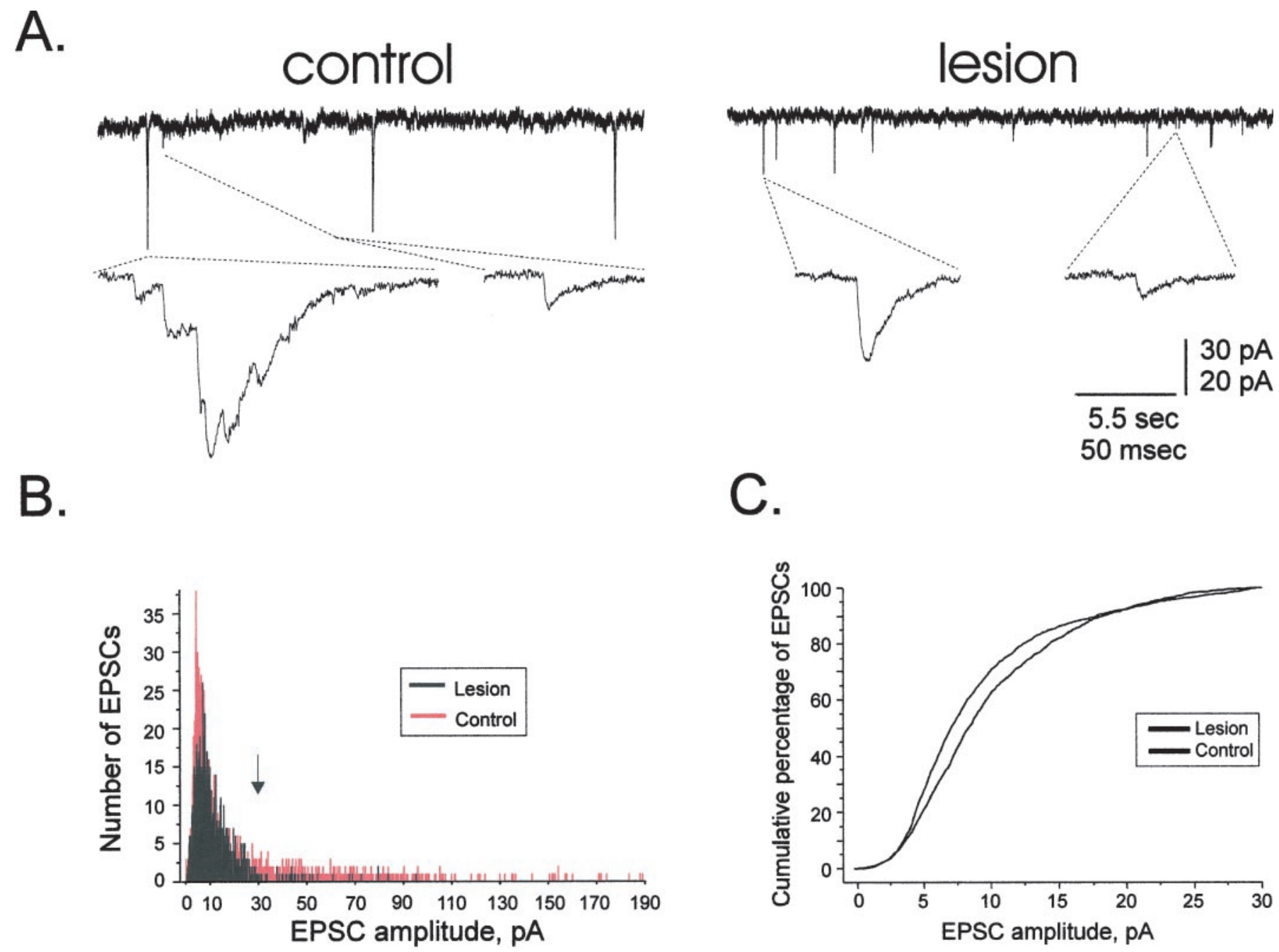

Figure 6. Unilateral LMAN lesions altered the amplitude distribution and types of spontaneous synaptic currents recorded in RA in brain slices made from juvenile animals. $A$, Top, Current records obtained in whole-cell voltage-clamp mode $\left(V_{\mathrm{h}}=-60 \mathrm{mV}\right)$ from RA neurons from either control (left) or LMAN-lesioned (right) hemispheres, in the presence of $50 \mu \mathrm{M}$ picrotoxin. Bottom, Representative large and small synaptic currents are shown on an expanded time scale (the upper and lower values next to the calibration bars correspond to the upper and lower current records, respectively). In control conditions, large amplitude, polyphasic currents occurred periodically, along with smaller amplitude, monophasic currents. In recordings from RA neurons in slices from the LMAN-lesioned hemisphere, only monophasic currents were observed; these varied in amplitude, and $>97.5 \%$ of them were $<30$ pA. B, A frequency histogram of all of the spontaneous synaptic currents recorded from RA neurons from control hemispheres, versus currents obtained from RA cells in LMAN-lesioned hemispheres. Note that the peak of the distribution for the events in "lesioned" cells is to the right of that for the control events, and that very large amplitude currents (i.e., $>100 \mathrm{pA}$ ) were detected only in control hemispheres. These larger events were the polyphasic currents shown on the left in $A$, whereas smaller events (i.e., $<30 \mathrm{pA}$; to the left of the arrow in $B$ ) were consistently monophasic. $C$, Cumulative amplitude distributions of monophasic EPSCs $(<30 \mathrm{pA})$ show a rightward shift in events measured in lesioned cells relative to controls. These distributions were significantly different $(p \ll 0.0001$, Kolmogorov-Smirnov test).

However, current records from control cells almost always (16 of 19 cells) contained periodic large $(>30 \mathrm{pA})$, complex, polyphasic currents (Fig. 6A, left) that were always absent ( 0 of 11 cells) in RA projection neurons from the LMAN-lesioned hemispheres. These events appear in the amplitude distribution (Fig. 6B) as a long tail of larger events in the control cells. In contrast to these complex events, smaller monophasic EPSCs were detected in RA projection neurons from both control and LMAN-lesioned hemispheres. Because we were most interested in directly comparing EPSCs in control versus lesioned conditions, we focused on the smaller, monophasic events that constituted the vast majority of events recorded in both experimental conditions (Fig. $6 A$, smaller events). Because all of the complex polyphasic events seen exclusively in the control cells were larger than $30 \mathrm{pA}$, we truncated the amplitude distributions for both populations, comparing only the distributions of events smaller than $30 \mathrm{pA}$. The pooled amplitude distribution for all lesioned cells shows a distinct rightward shift in the peak $<30 \mathrm{pA}$ relative to the corresponding amplitude distribution for control cells (Fig. 6B, main peaks). This is clearly shown in the cumulative probability distributions for EPSCs $<30$ pA (Fig. 6C), where the lesioned distribution is shifted significantly toward the right ( $p \ll 0.0001)$. When all of the EPSCs $<30$ pA were pooled across cells for each group, the average EPSC amplitude in LMAN-lesioned RA projection neurons was $10 \%$ larger than in control cells ( $p<0.0001 ; 10$ vs $9 \mathrm{pA})$, even though there was no difference in frequency of events or in series resistance between the two groups (Table 2). Although unilateral lesions were initially made to permit within-bird comparisons, in only one bird were we able to obtain long, stable recordings from more than one cell in both the control and LMAN-lesioned 
hemispheres. The data within this bird mirrored the data pooled across all birds: there was a significant $(p \ll 0.0001)$ rightward shift in the cumulative probability distribution and a significant (45\%: 11 vs 7 pA; $p<0.0001)$ increase in average EPSC amplitude for the pooled data $(<30 \mathrm{pA})$ from the lesioned side of this bird compared with the control side (data not shown). In summary, juvenile LMAN lesions are accompanied by an increase in the amplitude of small monophasic spontaneous EPSCs recorded in RA projection neurons, as well as the disappearance of periodic, more complex synaptic currents. Along with the changes in evoked synaptic transmission, these observations suggest that LMAN lesions induce functional changes in synaptic transmission within RA, including at the $\mathrm{HVc}-\mathrm{RA}$ synapse.

\section{DISCUSSION}

Our central finding is that juvenile LMAN lesions rapidly induce structural and functional changes in the vocal premotor nucleus RA. During the height of sensorimotor learning, we show that RA projection neurons exhibit pronounced morphological complexity relative to earlier and later development. LMAN lesions affect the dendritic spines and local axon collaterals of these juvenile RA neurons and alter the structure of extrinsic inputs from the song nucleus HVc. These structural effects are paralleled by changes in excitatory synaptic transmission that could alter vocal motor control and may partly explain why juvenile LMAN lesions disrupt song development.

The intracellular staining of RA projection neurons made here at different stages of development extends previous observations suggesting that RA in juveniles is structurally more complex than in fledglings or adults. Nissl studies indicate that juvenile RA volume and soma size are larger, and neuronal density is lower, than at earlier or later times, despite constant neuronal number (Bottjer et al., 1985; Konishi and Akutagawa, 1985; Herrmann and Bischof, 1986; Konishi and Akutagawa, 1987; Kirn and DeVoogd, 1989). Electron microscopy (EM) studies show elevated spine and synapse density in the juvenile RA, providing further support that these developmental differences reflect increased neuropil (Herrmann and Arnold, 1991). Our results specifically show that part of this overall increased synaptic complexity involves RA projection neurons, which directly control motoneurons used in singing (Nottebohm et al., 1976), and are a site of convergence between HVc and LMAN. These changes include elevated spine density and more extensive local collaterals. Because RA projection neuron dendritic spines receive input from $\mathrm{HVc}$ axons and axon collaterals of other RA neurons (Herrmann and Arnold, 1991), the increased spine density and collateral length suggest that the juvenile RA exhibits exuberant synaptic interconnectivity. In addition, examination of $\mathrm{HVc}$ axons themselves shows higher bouton frequency in the juvenile RA than in adults. This juvenile synaptic exuberance coincides with the peak of sensorimotor learning (Immelmann, 1969), when song is highly plastic and LMAN lesions most profoundly disrupt song development (Bottjer et al., 1984).

A major finding here is that, beyond their behavioral effects, LMAN lesions rapidly alter RA circuitry, resulting in decreased spine density, soma size and axon collateral complexity of RA projection neurons, and diminished $\mathrm{HVc}$ terminal bouton frequency within RA. These changes could explain why, beyond LMAN terminal elimination, RA volume declines slightly after juvenile LMAN lesions (Johnson and Bottjer, 1994). The decreased spine density is especially noteworthy, because it is unlikely to simply reflect the loss of LMAN terminals onto these spines. EM studies indicate that spinous RA neurons, including the projection neurons studied here, receive spine-type inputs predominantly (96-99\%) from intrinsic sources and from HVc; LMAN innervates no more than $5 \%$ of spine-type inputs at all ages after $\mathrm{HVc}$ robustly innervates RA (approximately PHD 30) (Konishi and Akutagawa, 1985; Canady et al., 1988; Herrmann and Arnold, 1991). Therefore, the $26 \%$ decline in spine density we saw after LMAN lesions likely reflects structural alterations beyond LMAN terminal elimination, such as the loss of other synaptic inputs. Furthermore, more than half (10 of 16) of the cells showed a decline in spine density greater than $50 \%$, whereas the remaining cells were unaffected in this parameter, perhaps because there are two functionally distinct classes of RA projection neurons or because the effects of LMAN lesions are stochastic and time dependent. Even if the fraction of dendritic spines innervated by LMAN is moderately higher than $5 \%$ at this juvenile time, it could not account for the extreme spine density reduction in this RA neuron subset.

Supporting the idea that spine density decreases after juvenile LMAN lesions involve the loss of other synaptic inputs onto RA projection neurons, we observed significant declines in $\mathrm{HVc}$ bouton frequency in RA and in RA projection neuron axon collateral complexity. HVc is the major extrinsic input onto RA dendritic spines (Canady et al., 1988; Herrmann and Arnold, 1991), and RA projection neuron axon collaterals are a major source of RA's intrinsic connections (Perkel, 1995), which are the most abundant spine-type input (Canady et al., 1988; Herrmann and Arnold, 1991). Furthermore, these inputs are both excitatory (Mooney and Konishi, 1991; Mooney, 1992; Perkel, 1995), and most excitatory inputs in the vertebrate CNS terminate onto spines (Harris and Kater, 1994). Taken together, these structural changes support the idea that LMAN lesions disrupt other synaptic connections onto RA projection neurons, including those from $\mathrm{HVc}$ and other RA neurons.

Indeed, juvenile LMAN lesions altered evoked synaptic transmission in RA: the stimulus-response relationship in RA projection neurons after $\mathrm{HVc}$ fiber stimulation became steeper in lesioned juveniles, resembling that of normal adults. Previous studies showed that such stimulation evokes monosynaptic, glutamatergic EPSPs at the short latencies examined here (Mooney and Konishi, 1991). Therefore, the present data suggest a strengthening of synaptic transmission between HVc and RA, both acutely after juvenile LMAN lesions and developmentally. However, two aspects of the evoked data may limit our ability to localize these effects to the HVc-RA synapse: (1) extremely fast polysynaptic components could contribute to the observed differences, and (2) differences in the response threshold in control juveniles relative to LMAN-lesioned juveniles and adults could also indicate increased excitability of the HVc fibers. Regardless, juvenile LMAN lesions rapidly altered synaptic transmission in RA in a manner similar to that occurring normally during sensorimotor development.

We recorded spontaneous EPSCs in RA to determine directly whether these changes in evoked responses reflected altered excitatory transmission. Monophasic EPSCs were larger in LMANlesioned juveniles than in controls, showing an augmentation of excitatory synaptic transmission. Recording conditions (i.e., $V_{\mathrm{h}}=$ $-60 \mathrm{mV}$, in picrotoxin) highlighted AMPA receptor-mediated EPSCs, via which the HVc-RA synapse operates, and masked NMDA receptor-mediated EPSCs (Mayer et al., 1984; Nowak et al., 1984), minimizing responses evoked by LMAN inputs in controls (Mooney, 1992). Furthermore, the spontaneous EPSC 
frequency was the same in control and lesioned hemispheres, which would not be expected if LMAN lesions merely increased $\mathrm{HVc}$ fiber excitability or if altered amplitude distributions simply reflected the loss of LMAN inputs. Taken together, the evoked and spontaneous data show that juvenile LMAN lesions alter synaptic transmission between $\mathrm{HVc}$ and RA.

In addition to altering the amplitudes of smaller, monophasic EPSCs, LMAN lesions also caused larger and more periodic spontaneous EPSCs to disappear. Such complex and rhythmic synaptic transmission can occur when neurons make recurrent excitatory connections (Traub and Miles, 1991), as do RA projection neurons. The absence of synaptic bursting in lesioned hemispheres could reflect altered intrinsic connectivity, a possibility supported by the reduced complexity of RA axon collaterals after LMAN lesions. Therefore, LMAN lesions may induce functional changes in RA's intrinsic as well as extrinsic synaptic connections.

Our data show that juvenile LMAN lesions, which derail song development, exert rapid and widespread effects on RA's structure and function. Adult LMAN lesions, however, which do not affect singing, do not alter $\mathrm{HVc}$ bouton frequency in RA, providing a correlation between the cellular and behavioral consequences of LMAN lesions. The age-limited behavioral effects of LMAN lesions have suggested both instructive and permissive roles for LMAN during sensorimotor learning (Bottjer et al., 1984; Scharff and Nottebohm, 1991; Mooney, 1992; Doupe et al., 1999). The present study does not distinguish between these two roles, but it does show that using LMAN lesions to deduce normal LMAN function is complicated by the perturbation that these lesions cause to RA in young birds.

These results show that LMAN lesions do not disrupt song learning by arresting RA neuronal development in a juvenile state and are instead consistent with a trophic model in which LMAN maintains RA's phenotype in normal juveniles. Furthermore, juvenile LMAN lesions induced progressive changes: RA neurons from lesioned birds resembled those of adults, and not fledglings, in terms of axon collateral length and complexity, dendritic spine number and density, current-frequency relation, and spike accommodation rate (Tables 1, 2). Additionally, the stimulus-response function evoked at the HVc-RA synapse and the HVc synaptic bouton frequency within RA were adultlike in lesioned juveniles, parameters that are unobtainable in fledglings because HVc has not innervated RA (Konishi and A Kutagawa, 1985; Mooney, 1992).

Other evidence that LMAN supplies trophic support for RA development is that (1) early LMAN lesions cause massive RA cell death, which can be rescued by infusion of neurotrophins, including BDNF (Johnson et al., 1997), (2) BDNF can be anterogradely transported from LMAN to RA (Johnson et al., 1997), and (3) BDNF expression is developmentally regulated, with highest expression in RA coinciding with the height of sensorimotor learning (Akutagawa and Konishi, 1998). Activitydependent expression of neurotrophins can homeostatically regulate synaptic strength (Rutherford et al., 1997, 1998). Evidence shows that homeostatic regulation can involve activity-dependent compensatory changes in synapse number and strength (Zou and Cline, 1996; Davis and Goodman, 1998; Turrigiano et al., 1998; Wu and Cline, 1998) (for review, see Turrigiano, 1999). Perhaps LMAN provides trophic influences, which could in part depend on song-evoked patterns of activity (Doupe and Konishi, 1991; Doupe, 1997; Solis and Doupe, 1997; Jarvis et al., 1998; Hessler and Doupe, 1999) that maintain a high number of weak connec- tions in the developing RA. As LMAN terminal density within RA declines over late sensorimotor learning (Herrmann and Arnold, 1991), decreased trophic support could trigger consolidation of remaining inputs. The present results, which show that juvenile LMAN lesions decrease the number of presynaptic and postsynaptic structures in RA, with compensatory increases in the functional strength of those that remain, may point to future experiments that examine whether compensatory processes regulate synaptic connectivity in RA during development and song learning.

\section{REFERENCES}

Akutagawa E, Konishi M (1994) Two separate areas of the brain differentially guide the development of a song control nucleus in the zebra finch. Proc Natl Acad Sci USA 91:12413-12417.

Akutagawa E, Konishi M (1998) Transient expression and transport of brain-derived neurotrophic factor in the male zebra finch's song system during vocal development. Proc Natl Acad Sci USA 95:11429-11434.

Bottjer SW, Miesner EA, Arnold AP (1984) Forebrain lesions disrupt development but not maintenance of song in passerine birds. Science 224:901-903.

Bottjer SW, Glaessner SL, Arnold AP (1985) Ontogeny of brain nuclei controlling song learning and behavior in zebra finches. J Neurosci $5: 1556-1562$.

Bottjer SW, Halsema KA, Brown SA, Miesner EA (1989) Axonal connections of a forebrain nucleus involved with vocal learning in zebra finches. J Comp Neurol 279:312-326.

Canady RA, Burd GD, DeVoogd TJ, Nottebohm F (1988) Effect of testosterone on input received by an identified neuron type of the canary song system: a golgi/electron microscopy/degeneration study. J Neurosci 8:3770-3784.

Davis GW, Goodman CS (1998) Synapse-specific control of synaptic efficacy at the terminals of a single neuron. Nature 392:82-86.

Doupe AJ (1997) Song- and order-selective neurons in the songbird anterior forebrain and their emergence during vocal development. J Neurosci 17:1147-1167.

Doupe AJ, Konishi M (1991) Song-selective auditory circuits in the vocal control system of the zebra finch. Proc Natl Acad Sci USA 88:11339-11343.

Doupe AJ, Brainard MS, Hessler NA (1999) The song system: neural circuits essential throughout life for vocal behavior and plasticity. In: The cognitive neurosciences (Gazzaniga M, ed), Cambridge, MA: MIT Press, in press.

Harris KM, Kater SB (1994) Dendritic spines: cellular specializations imparting both stability and flexibility to synaptic function. Annu Rev Neurosci 17:341-371.

Herrmann K, Arnold A (1991) The development of afferent projections to the robust archistriatal nucleus in male zebra finches: a quantitative electron microscopic study. J Neurosci 11:2063-2074.

Herrmann K, Bischof H-J (1986) Delayed development of song control nuclei in the zebra finch is related to behavioral development. J Comp Neurol 245:167-175.

Hessler NA, Doupe AJ (1999) Social context modulates singing-related neural activity in the songbird forebrain. Nat Neurosci 2:209-211.

Immelmann K (1969) Song development in the zebra finch and other estrildid finches. In: Bird vocalizations (Hinde RA, ed), pp 61-74. Cambridge: Cambridge UP.

Jarvis ED, Scharff C, Grossman MR, Ramos JA, Nottebohm F (1998) For whom the bird sings: context-dependent gene expression. Neuron 21:775-788.

Johnson F, Bottjer SW (1994) Afferent influences on cell death and birth during development of a cortical nucleus necessary for learned vocal behavior in zebra finches. Development 120:13-24.

Johnson F, Hohmann SE, DiStefano PS, Bottjer SW (1997) Neurotrophins suppress apoptosis induced by deafferentation of an avian motorcortical region. J Neurosci 17:2101-2111.

Kirn JR, DeVoogd TJ (1989) Genesis and death of vocal control neurons during sexual differentiation in the zebra finch. J Neurosci 9:3176-3187.

Konishi M (1965) The role of auditory feedback in the control of vocalization in the white-crowned sparrow. Z Tierpsychol 22:770-783.

Konishi M, Akutagawa E (1985) Neuronal growth, atrophy and death in 
a sexually dimorphic song nucleus in the zebra finch brain. Nature 315:145-147.

Konishi M, Akutagawa E (1987) Hormonal control of cell death in a sexually dimorphic song nucleus in the zebra finch. Ciba Found Symp: Selective Neuronal Death 126:173-185.

Livingston FS, Mooney R (1997) Development of intrinsic and synaptic properties in a forebrain nucleus essential to avian song learning. J Neurosci 17:8997-9009.

Mayer ML, Westbrook GL, Guthrie PB (1984) Voltage-dependent block by $\mathrm{Mg}^{2+}$ of NMDA responses in spinal cord neurones. Nature 309:261-263.

McCasland JS (1987) Neuronal control of bird song production. J Neurosci 7:23-39.

Mooney R (1992) Synaptic basis for developmental plasticity in a birdsong nucleus. J Neurosci 12:2464-2477.

Mooney R (1999) Sensitive periods and circuits for learned birdsong. Curr Opin Neurobiol 9:121-127.

Mooney R, Konishi M (1991) Two distinct inputs to an avian song nucleus activate different glutamate receptor subtypes on individual neurons. Proc Natl Acad Sci USA 88:4075-4079.

Nottebohm F, Stokes TM, Leonard CM (1976) Central control of song in the canary, Serinus canarius. J Comp Neurol 165:457-486.

Nottebohm F, Kelley DB, Paton JA (1982) Connections of vocal control nuclei in the canary telencephalon. J Comp Neurol 207:344-357.

Nowak L, Bregestovski P, Ascher P, Herbet A, Prochiantz A (1984) Magnesium gates glutamate-activated channels in mouse central neurones. Nature 307:462-465.

Okuhata S, Saito N (1987) Synaptic connections of a forebrain nucleus involved with vocal learning in zebra finches. Brain Res Bull 18:35-44.

Perkel DJ (1995) Effects of neuromodulators on excitatory synaptic transmission in nucleus RA of the zebra finch. Soc Neurosci Abstr 21:960.

Price PH (1979) Developmental determinants of structure in zebra finch song. J Comp Physiol [A] 93:260-277.

Rutherford L, DeWan A, Lauer H, Turrigiano G (1997) Brain-derived neurotrophic factor mediates the activity-dependent regulation of inhibition in neocortical cultures. J Neurosci 17:4527-4535.

Rutherford LC, Nelson SB, Turrigiano GG (1998) BDNF has opposite effects on the quantal amplitude of pyramidal neuron and interneuron excitatory synapses. Neuron 21:521-530.
Scharff C, Nottebohm F (1991) A comparative study of the behavioral deficits following lesions of various parts of the zebra finch song system: implications for vocal learning. J Neurosci 11:2896-2913.

Sholl DA (1954) Dendritic organization in the neurons of the visual and motor cortices of the cat. J Anat 87:387-407.

Simpson HB, Vicario DS (1990) Brain pathways for learned and unlearned vocalizations differ in zebra finches. J Neurosci 10:1541-1556.

Slater PJB, Eales LA, Clayton NS (1988) Song learning in zebra finches (Taeniopygia guttata): progress and prospects. Adv Study Behav $18: 1-34$.

Solis MM, Doupe AJ (1997) Anterior forebrain neurons develop selectivity by an intermediate stage of birdsong learning. J Neurosci 17:6447-6462.

Spiro JE, Dalva MB, Mooney R (1999) Long-range inhibitory circuits in a forebrain nucleus critical for production of learned birdsong. J Neurophysiol 81:3007-3020.

Traub RD, Miles R (1991) Neuronal networks of the hippocampus. New York: Cambridge UP.

Turrigiano GG (1999) Homeostatic plasticity in neuronal networks: the more things change, the more they stay the same. Trends Neurosci 22:221-227.

Turrigiano GG, Leslie KR, Desai NS, Rutherford LC, Nelson SB (1998) Activity-dependent scaling of quantal amplitude in neocortical neurons. Nature 391:892-896.

Vicario DS (1993) A new brain stem pathway for vocal control in the zebra finch song system. NeuroReport 4:983-986.

Wild JM (1993a) Descending projections of the songbird nucleus robustus archistriatalis. J Comp Neurol 338:225-241.

Wild JM (1993b) The avian nucleus retroambigualis: a nucleus for breathing, singing and calling. Brain Res 606:119-124.

Wu G-Y, Cline HT (1998) Stabilization of dendritic arbor structure in vivo by CaMKII. Science 279:222-226.

Yu AC, Margoliash D (1996) Temporal hierarchical control of singing in birds. Science 273:1871-1875.

Zar JH (1996) Biostatistical analysis. Upper Saddle River, NJ: Prentice Hall.

Zou D-J, Cline HT (1996) Expression of constitutively active CaMKII in target tissue modifies presynaptic axon arbor growth. Neuron 16: $529-539$. 